\title{
An Effective Constitutive Model for Lime Treated Soils
}

\author{
V. Robin ${ }^{1,2}$, A. A. Javadi ${ }^{1}$, O. Cuisinier ${ }^{2}$, F. Masrouri ${ }^{2}$ \\ ${ }^{1}$ Computational Geomechanics Group, Department of Engineering, University of Exeter, United-Kingdom \\ ${ }^{2}$ LEMTA - UMR 7563 CNRS, Laboratoire d'Energétique et de Mécanique Théorique et Appliquée, Université de Lorraine, \\ France
}

\section{Abstract}

The effect of lime on the yield stress, and more generally the presence of structure in the soil, is usually not accounted for in the design of geotechnical structures. As a result the potential of lime treatment or of a structured soil has not been fully exploited. This paper presents a new formulation to account for the effect of structure on the mechanical behaviour for structured soils. A constitutive model is proposed in the framework of the Modified Cam Clay model to describe the behaviour of lime treated soils. The new formulation introduces a limited number of additional parameters, all of which have a physical meaning and can be obtained from an isotropic compression test. Due to similarity in behaviour of lime treated soils and naturally structured soils, the formulation can be applied to both types of soil. It is shown that the proposed model can successfully reproduce the main features of both structured soils such as maximum rate of dilation at softening and degradation at yield. The model can be applied for any structured material regardless of the origin of cementation.

7 Keywords:

8 lime treated soils, structured soils, degradation, constitutive modelling.

\section{Introduction}

The use of on-site materials has become a central issue for civil engineering companies, but it is sometimes difficult to deal with all the resources available on site. For soils with low mechanical characteristics, lime treatment appears to be an efficient method to improve their mechanical properties and allow their use in geotechnical earth structures (e.g. Little, 1995). The effects of the addition of lime on the soil parameters such as cohesion and friction angle have been extensively studied (e.g. Brandl, 1981). Nevertheless, lime is still mostly used to dry soils with high water contents and increase the bearing capacity. However, it is also generally known that adding lime leads to a significant increase of the yield stress and modifies other mechanical parameters in compacted soils. In lime-treated soils, the modification of the mechanical behaviour results from several physico-chemical processes associated with the increase in calcium concentration and pH (i.e. cation exchange, pozzolanic reactions, etc...). 
From an economical point of view, it is becoming increasingly important to account for the properties of treated materials in the design of the geotechnical structures. However, despite its proven efficacy, the use of treated materials suffers from several major drawbacks: there is no reliable method to account for the structure in the calculations. At yield, and for an increasing mechanical loading, treated materials experience what is called the "loss of structure", resulting in the degradation of the structure in different ways. To model the behaviour of these materials, a constitutive law describing the behaviour at yield is a requirement.

Some studies (Maccarini, 1987; Aversa, 1991; Leroueil and Vaughan, 1990; Liu and Carter, 2003; Flora et al., 2006) have shown that naturally structured soils and artificially treated materials have common mechanical features; artificial treatment appears to create a "structure" in the soil. In this paper, "structure" refers to Burland's definition (Burland, 1990), and is seen as the combination of the fabric and the bonding of the soil skeleton. Fabric accounts for the arrangement of particles, which depends on the state of compaction and their geometry.

Several constitutive models have been proposed for structured materials. Most of these models use the destructured state as reference to describe the mechanical behaviour of structured soils. Liu and Carter (2002) proposed a constitutive model, based on the Modified Cam Clay model (MCC), by adding three additional parameters to the original MCC (Roscoe and Burland, 1968). Since then, several enhancements (e.g. Horpibulsuk et al., 2010; Suebsuk et al., 2011) have been proposed. However, various modes of destructuration have been identified, and the original formulation fails to model some of them. A number of other formulations have been developed (Kavvadas and Amorosi, 2000; Vatsala et al., 2001; Nova et al., 2003; Baudet and Stallebrass, 2004; Rouainia and Muir wood, 2000; Nguyen et al., 2014) and some of which give good agreement with experimental results. However, it often comes at the cost of a larger number of parameters, or high computational resources (e.g. mapping rule). Parameters do not always have a physical meaning, and some of them can be difficult to determine. All these limitations make these models difficult to be used in engineering practice.

The main objective of this paper is to propose a general and simple formulation capable of fulfilling some fundamentals criteria regarding the degradation of the structure. This model must be capable of modelling any kind of degradations, and require a limited number of parameters to account for the maximum number of features of structured materials. These parameters should be rapidly obtained from classic experimental tests, and they all must have a physical meaning. To this end, the paper will focus on two aspects:

- How can the key features of structured or lime treated materials be described?

- How can these features be efficiently accounted for in a constitutive model?

This paper is divided into four parts. The first part gives a review of the main characteristics of naturally and artificially structured materials that must be reproduced by the model. The second part introduces the 
theoretical framework chosen for the model for lime treated soils (MLTS) and the new formulation developed to model the degradation of the structure. In the third part, the developed formulation is used to calculate the compliance matrix and obtain the stress-strain relationship. Finally, in the last part, we assess the suitability of the model in predicting experimental results obtained from triaxial tests on artificially (i.e. lime treated) and naturally structured materials.

\section{Features of structured soils}

The mechanical behaviour of naturally and artificially structured material has been extensively studied (Leroueil and Vaughan, 1990; Gens and Nova, 1993; Burland et al., 1996; Cotecchia and Chandler, 2000; Malandraki and Toll, 2001; Cuisinier et al., 2008, 2011; Consoli et al., 2011; Oliveira, 2013; Robin et al., 2014a) and some specific features have been identified. Several studies have pointed out that naturally and artificially structured soils have a similar mechanical behaviour. In this section, we identify the key features common to naturally and artificially structured soils that should be properly reproduced by a model.

\subsection{Naturally structured soils}

It has been shown that naturally structured soils have a higher yield stress compared to the destructured state (Burland et al., 1996), the latter being usually considered as the reference state. For the same stress state, a higher yield stress leads to a higher void ratio at yield compared to the destructured state, called the additional void ratio $\Delta e$. Once plastic deformations take place, one can observe that the additional void ratio decreases. Depending on the material, the additional void ratio can quickly or slowly decrease until the material reaches a normal compression line (ncl), which can correspond to the ncl of the reference state $\left(\mathrm{ncl}_{\mathrm{d}}\right)$, or a different one, parallel to the reference ncl but vertically translated along the $v$ axis (ncl $\left.\mathrm{r}_{\mathrm{r}}\right)$ (Baudet and Stallebrass, 2004; Callisto and Rampello, 2004; Suebsuk et al., 2011). More generally, 4 modes of degradation can be identified (Figure 1):

Mode 1: Destructuration takes place immediately at yield. The additional void ratio progressively decreases until it converges toward the destructured state (Yong and Nagaraj, 1977; Lagioia and Nova, $1995)$.

Mode 2: Destructuration takes place immediately at yield, but it does not converge toward its destructured state. A different ncl appears parallel to the destructured state, but a residual additional void ratio still remains (Burland et al., 1996; Rampello and Callisto, 1998).

Mode 3: No significant destructuration is observed immediately after yield. The process of degradation is initiated later on for a higher effective mean stress and the additional void ratio completely disappears (Callisto and Rampello, 2004). 
Mode 4: No destructuration is observed immediately after yield. The process of degradation is initiated later on for a higher effective mean stress. However, a residual additional void ratio remains (Rotta et al., 2003).

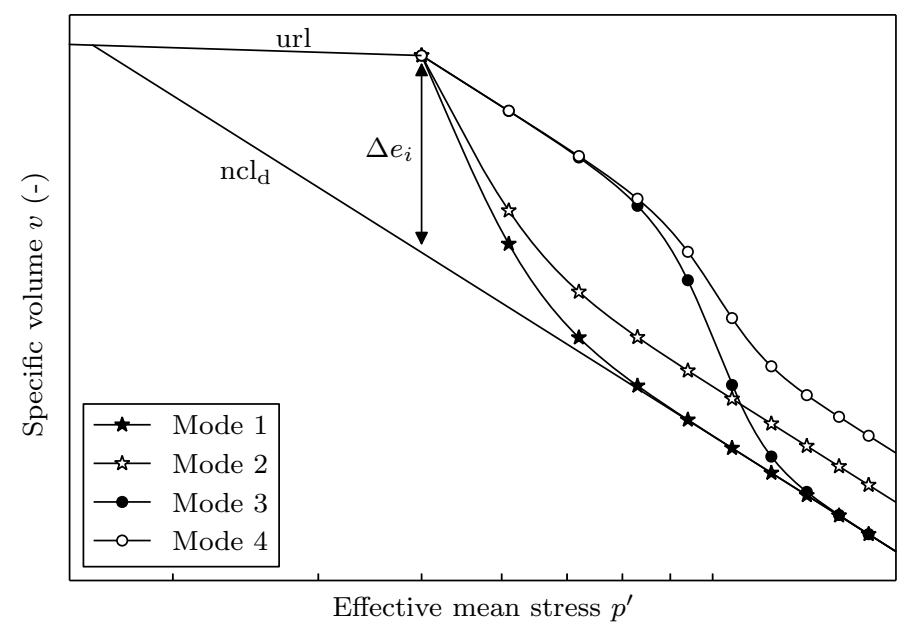

Figure 1: The four different modes of destructuration in structured soils $-\mathrm{ncl}_{\mathrm{d}}$ : Normal compression line of the destructured state, url: Unloading-reloading line.

Additionally, the volumetric behaviour of naturally structured soils was compared with the destructured state by Leroueil and Vaughan (1990) on heavily overconsolidated specimens from drained triaxial test results. They identified two different mechanisms taking place. While the maximum rate of dilation was measured before the peak of the deviatoric stress for the destructured soil, it was observed after the peak of the deviatoric stress for structured soils. This is due to the structure, which binds soil particles together. To allow the particles to move freely, the structure has to be degraded first to release particles (Leroueil and Vaughan, 1990).

\subsection{Lime treated soils}

Several studies have shown that addition of lime leads to an increase of the yield stress compared to the untreated state (Tremblay et al., 2001; Ahnberg, 2007). As for naturally structured soils, the additional void ratio appears to decrease at yield, i.e. the degradation of the artificial structure takes place. Robin et al. (2014a) have assessed the mechanical behaviour of a lime treated silt under isotropic loading (Figure 2). It can be seen that the mode of degradation depends on the amount of lime. For $0.5 \%$ in lime, the additional void ratio completely disappears at high stress states (Mode 3 ), when it is not the case for $1 \%$ lime treated specimens (Mode 4). This latter reaches a different ncl compared to the untreated specimen. Details about the samples and experimental conditions can be found in Robin et al. (2014a). 


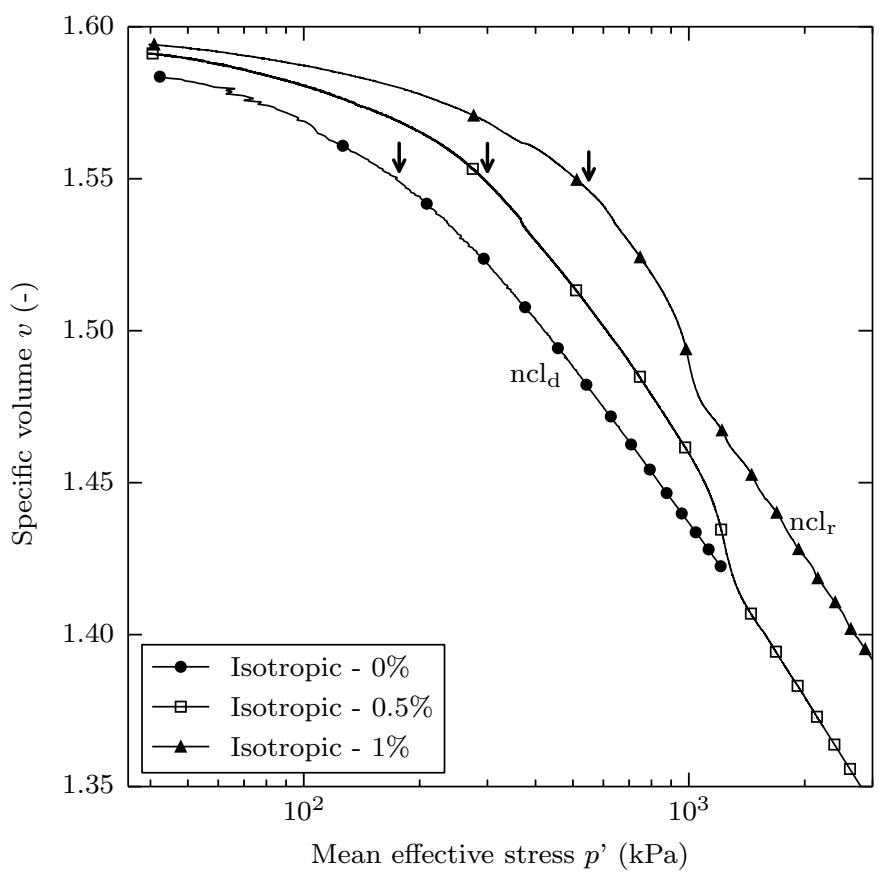

Figure 2: Isotropic consolidation curves obtained from specimens of silt treat at $0.5 \%$ and $1 \%$ in lime - Arrows mark the yield stress $p_{y}^{\prime}, \mathrm{ncl}_{\mathrm{d}}$ : Normal compression line of the destructured state, $\mathrm{ncl}_{\mathrm{r}}$ : Normal compression line of the residual state (Robin et al., 2014a).

The maximum rate of dilation at shear for specimens experiencing softening also appears after the peak for artificially structured soils, which indicates that the same kind of mechanism is taking place. This common feature was pointed out by Leroueil and Vaughan (1990), and was also observed for the lime treated specimens from the current study (Figure 3). 

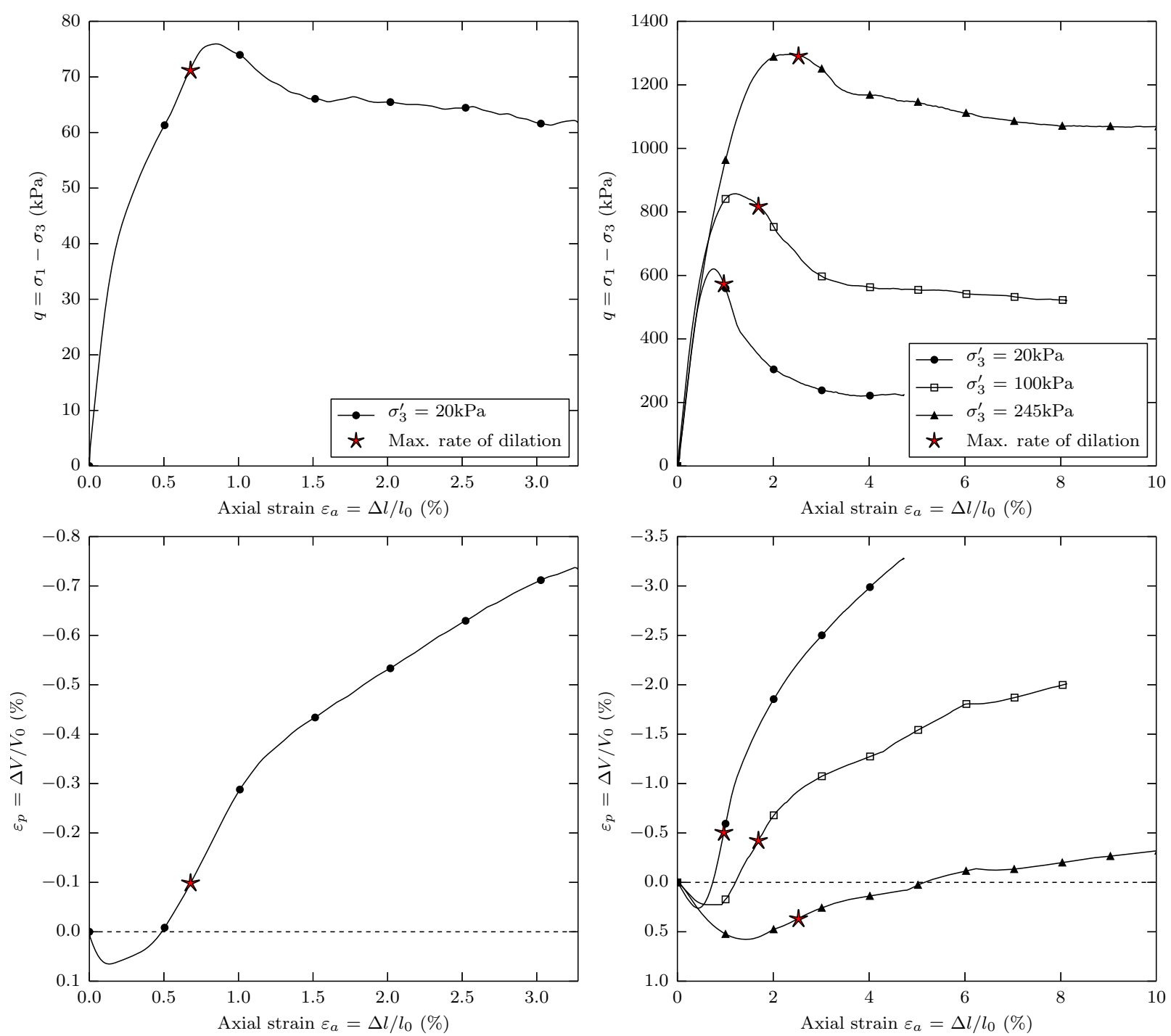

(a) $[\mathrm{CaO}]=0 \%$

(b) $[\mathrm{CaO}]=5 \%$

Figure 3: Drained triaxial results on (a) untreated and (b) lime treated soils - Stars mark the location where the rate of dilation is maximum (Robin et al., 2014a).

The influence of a lime treatment on the cohesion and the friction angle has been studied by several authors (Wissa et al., 1965; Balasubramaniam et al., 2005). Both cohesion and friction angle appear to increase with the amount of lime. The slope of the critical state line is directly related to the friction angle, and the increase of cohesion, which increases the tensile strength, has an influence on the shape of the yield function. Therefore, in the framework the critical state theory, these features should be accounted for in the model. 


\subsection{Summary}

Based on the previous observations, a model for lime treated soils might be suitable for naturally structured soils, and therefore should be able to reproduce the four modes of destructuration and account for the following features:

- The cohesion increases following pozzolanic reactions,

- The yield stress increases for lime treated soils compared to the reference state,

- At yield, there exists an additional void ratio compared to the reference state,

- At yield, degradation of the structure takes place, which follows one of the four modes identified previously,

- Overconsolidated specimens at shear show a maximum rate of dilation after the peak, describing the degradation of the structure,

- The friction angle is modified due to the effects of the chemical reactions on the texture of the soil, and therefore the critical state as well.

\section{Theoretical framework of the model}

The model proposed in this paper was developed in the framework of the Modified Cam Clay model (MCC) to model the key features of lime treated soils previously identified. The new parameters introduced to model the degradation have all a physical meaning and can be determined from an isotropic compression test (Robin et al., 2014b). We present in this section a new formulation to model the four modes of degradation in structured soils under isotropic loading. This will then be used as a hardening rule for the determination of the compliance matrix.

\subsection{Modelling the structure and its degradation under isotropic loading}

To model the degradation of the structure under isotropic loading, we propose the framework given in Figure 4. We introduce the primary yield stress $p_{y}^{\mathrm{I}}$, which corresponds to the apparition of plastic deformations. To describe the stress states for which the degradation of the structure takes place (hatched area in Figure 4), we also introduce the degradation stress $p_{y}^{\mathrm{II}}$. In the case of an immediate degradation of the structure at yield (modes $1 \& 2$ in Figure 1), which can happen for some structured soils, we have $p_{y}^{\mathrm{II}}=p_{y}^{\mathrm{I}}$. The additional void ratio $\Delta e_{i}$ at $p_{y}^{\mathrm{I}}$ quantifies the initial additional void ratio at yield. $\Delta e_{c}$ is measured at an effective mean stress above which the additional void ratio remains constant $\left(p^{\prime} \gg p_{y}^{\mathrm{II}}\right)$. By setting the parameters as given in Table 1, this framework is capable of describing the four modes of degradation. 
In this study, the structure is quantified through the additional void ratio in comparison to the ncl $l_{d}$ and is assumed to be made of two components. The first one, referred to as the available structure, corresponds to the part of structure that will be available during the process of destructuration $\left(\Delta e_{i}-\Delta e_{c}\right)$. The second one, referred to as the residual structure, corresponds to the persisting additional void ratio at high effective mean stress $\left(\Delta e_{c}\right.$ at $\left.p^{\prime} \gg p_{y}^{\mathrm{I}}\right)$. The latter can be the consequences of chemical reactions, e.g. a lime treatment, which leads to a permanent modification of the fabric of the soil (Robin et al., 2014a).

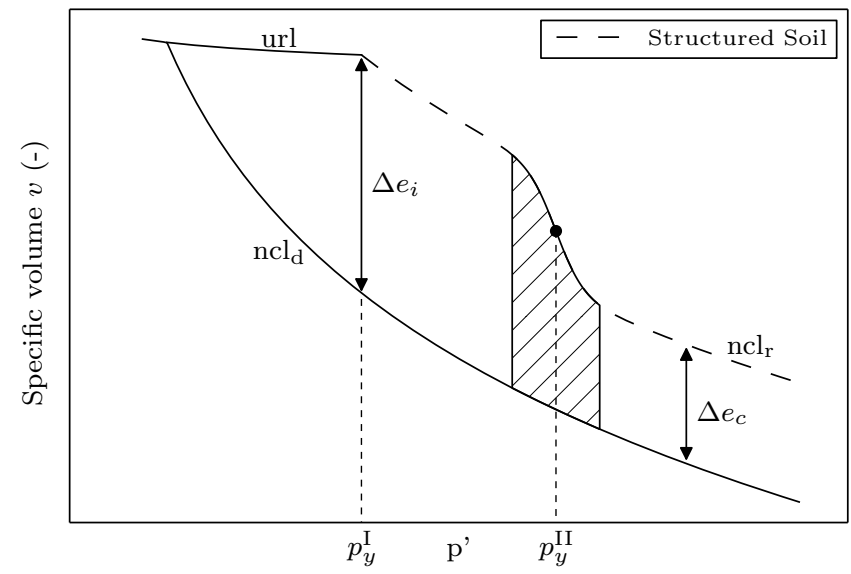

Figure 4: General framework of the degradation of structured soils $-\Delta e_{i}$ : Initial additional void ratio, $\Delta e_{c}$ : Residual additional void ratio, $p_{y}^{\mathrm{I}}$ : Primary yield stress, $p_{y}^{\mathrm{II}}$ : degradation stress, hatched area: degradation of the structure, ncl ${ }_{\mathrm{d}}$ : Normal compression line of the destructured state, $\mathrm{ncl}_{\mathrm{r}}$ : Normal compression line of the residual state, url: Unloading-reloading line.

Table 1: Conditions on the parameters $p_{y}^{\mathrm{II}}$ and $\Delta e_{c}$ for the 4 modes of degradation

\begin{tabular}{ccccc}
\hline & \multicolumn{4}{c}{ Values } \\
\cline { 2 - 5 } Parameters & Mode 1 & Mode 2 & Mode 3 & Mode 4 \\
\hline$p_{y}^{\mathrm{II}}$ & $p_{y}^{\mathrm{I}}$ & $p_{y}^{\mathrm{I}}$ & $>p_{y}^{\mathrm{I}}$ & $>p_{y}^{\mathrm{I}}$ \\
$\Delta e_{c}$ & 0 & $>0$ & 0 & $>0$ \\
\hline
\end{tabular}

\subsubsection{Mathematical Formulation}

To model these four mechanisms, a flexible formulation using all the parameters previously introduced is required. Richards's equation (Richards, 1959) for the sigmoid provides many degrees of freedom to control the shape of the function. This function is frequently used for the modelling natural phenomenons where there exists a threshold above which a process is activated, in this case the degradation. This equation can be written as follows:

$$
\forall p^{\prime} \in\left[p_{y}^{\mathrm{I}},+\infty\left[\pi\left(p^{\prime}\right)=1-\frac{1}{1+e^{-\beta\left(p^{\prime}-p_{y}^{\mathrm{II}}\right)}}\right.\right.
$$




\subsubsection{Scaling of $\pi$}

The function $\pi$ is scaled to ensure that $\forall \beta, \forall p_{y}^{\mathrm{II}} \pi\left(p_{y}^{\mathrm{I}}\right)=1$, which leads to the following final formulation:

$$
\forall p^{\prime} \in\left[p_{y}^{\mathrm{I}},+\infty\left[\quad \pi\left(p^{\prime}\right)=\frac{e^{\beta p_{y}^{\mathrm{I}}}+e^{\beta p_{y}^{\mathrm{II}}}}{e^{\beta p^{\prime}}+e^{\beta p_{y}^{\mathrm{II}}}}\right.\right.
$$

where $p_{y}^{\mathrm{II}}[\mathrm{Pa}]$ corresponds to the position of the inflection point $\left(\pi^{\prime \prime}\left(p_{y}^{\mathrm{II}}\right)=0\right)$ and describes the stress state for which the degradation occurs (hatched area in Figure 4), and $\beta\left[\mathrm{Pa}^{-1}\right]$ describes the rate of degradation.

Therefore, we have

$$
\forall p^{\prime} \in \mathbb{R} \quad 0 \leq \pi\left(p^{\prime}\right) \leq 1
$$

which verifies $\pi\left(p_{y}^{\mathrm{I}}\right)=1$ and $\lim _{p^{\prime} \rightarrow+\infty} \pi\left(p^{\prime}\right)=0$.

The ability to control the rate of degradation at yield of this formulation is demonstrated in Figure 5 . It can be seen that the function $\pi$ can either slowly decrease with a low $\beta$ or quickly with a high $\beta$ as $p^{\prime}$ gets close to $p_{y}^{\mathrm{II}}$.

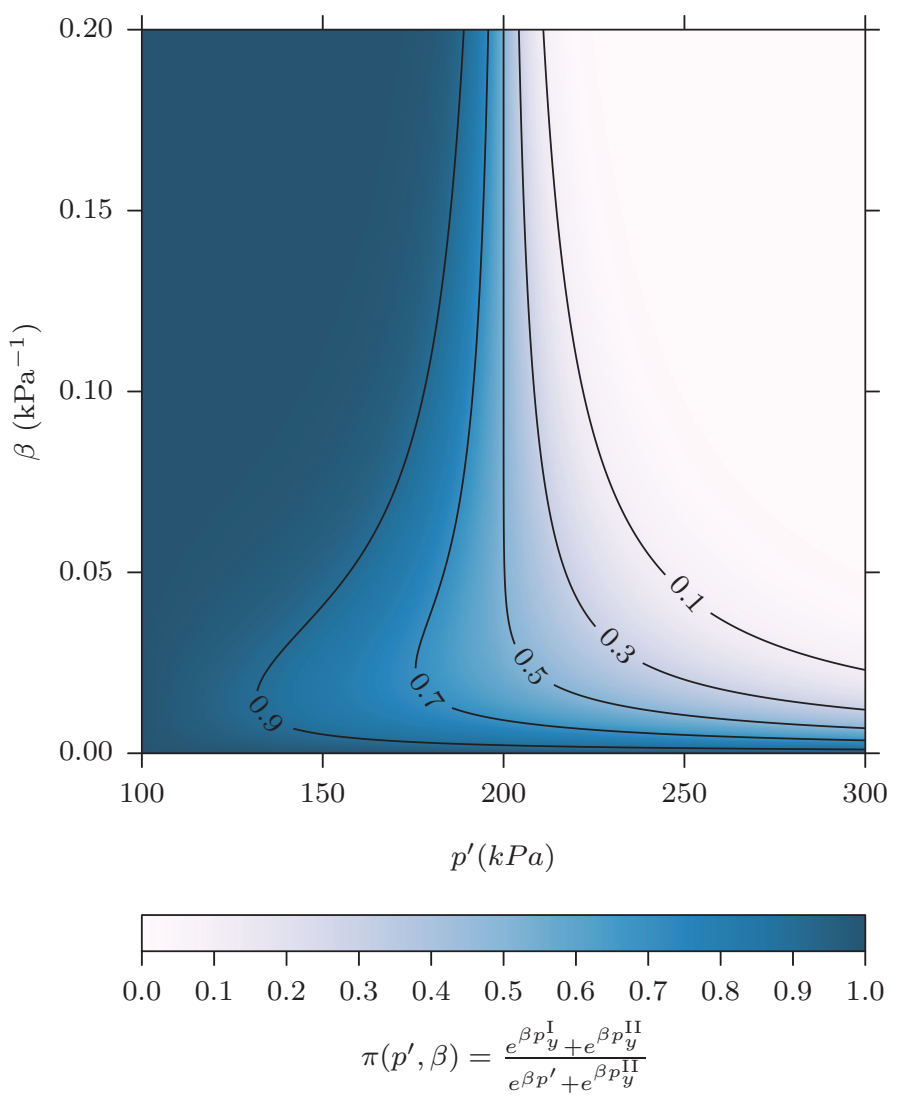

Figure 5: $\pi$ values as a function of $p_{y}^{\mathrm{II}}$ and $\beta-p_{y}^{\mathrm{I}}=100 \mathrm{kPa}, p_{y}^{\mathrm{II}}=200 \mathrm{kPa}$. 


\subsubsection{Relationship between the specific volume and the effective mean stress for structured soils}

The presence of structure can be accounted for in the relationship between the specific volume and the effective mean stress $\left(v: p^{\prime}\right.$ relationship) using the following general formulation:

$$
\forall p^{\prime} \in \mathbb{R}_{+}^{*} \quad v\left(p^{\prime}\right)=N_{\lambda}-\lambda \ln \left(p^{\prime}\right)+\Delta e\left(p^{\prime}\right)
$$

with $N_{\lambda}$ the intercept on the reference normal compression line $\mathrm{ncl}_{\mathrm{d}}$ and $\lambda$ the slope of the reference ncl in $v: \ln \left(p^{\prime}\right)$ plane.

Using the function $\pi$ (Equation 3), the equation for the additional void ratio is given by:

$$
\forall p^{\prime} \in\left[p_{y}^{\mathrm{I}},+\infty\left[\quad \Delta e\left(p^{\prime}\right)=\left(\Delta e_{i}-\Delta e_{c}\right) \cdot\left[\frac{e^{\beta p_{y}^{\mathrm{I}}}+e^{\beta p_{y}^{\mathrm{II}}}}{e^{\beta p^{\prime}}+e^{\beta p_{y}^{\mathrm{II}}}}\right]+\Delta e_{c}\right.\right.
$$

which fulfils the boundary value problems:

$$
\Delta e\left(p^{\prime}\right)= \begin{cases}\Delta e_{i} & \text { if } p^{\prime}=p_{y}^{\mathrm{I}} \\ \Delta e_{c} & \text { if } p^{\prime} \rightarrow+\infty\end{cases}
$$

Introducing Equation 5 in Equation 4 gives the final equation of the specific volume for structured soils at yield:

$$
\forall p^{\prime} \in\left[p_{y}^{\mathrm{I}},+\infty\left[\quad v_{s}\left(p^{\prime}\right)=N_{\lambda}-\lambda \ln \left(p^{\prime}\right)+\left(\Delta e_{i}-\Delta e_{c}\right) \cdot\left[\frac{e^{\beta p_{y}^{\mathrm{I}}}+e^{\beta p_{y}^{\mathrm{II}}}}{e^{\beta p^{\prime}}+e^{\beta p_{y}^{\mathrm{II}}}}\right]+\Delta e_{c}\right.\right.
$$

\subsubsection{Determination of $\beta$}

$\beta$ can be directly determined from the results of an isotropic compression test. Practically, $\beta$ is related to the gradient $\xi$ on the $v: p^{\prime}$ curve at $p^{\prime}=p_{y}^{\mathrm{II}}$ (Figure 6). For consistency and stability, the function $v_{s}$ for the specific volume in the $v: p^{\prime}$ plane must be strictly monotonic decreasing on $\left[p_{y}^{\mathrm{I}},+\infty[\right.$, which imposes $\beta \geq 0$.

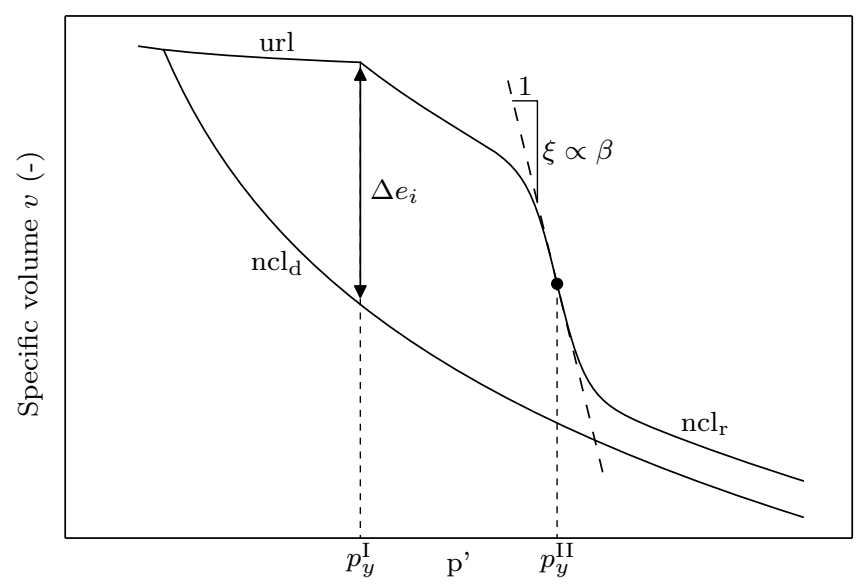

Figure 6: Physical meaning of $\beta-\mathrm{ncl}_{\mathrm{d}}$ : Normal compression line of the destructured state, ncl $\mathrm{r}$ : Normal compression line of the residual state, url: Unloading-reloading line. 
Calling $\xi$ the gradient of the specific volume curve at $p^{\prime}=p_{y}^{\mathrm{II}}$, the appropriate value for $\beta$ is obtained by solving the following equation:

$$
\left(\frac{d v}{d p^{\prime}}\right)_{p^{\prime}=p_{y}^{\mathrm{II}}}=\xi \quad \Leftrightarrow \quad-\frac{1}{4}\left(1+e^{\beta\left(p_{y}^{\mathrm{I}}-p_{y}^{\mathrm{II}}\right)}\right) \times \beta\left(\Delta e_{i}-\Delta e_{c}\right)-\frac{\lambda}{p_{y}^{\mathrm{II}}}=\xi
$$

There is no analytical solution to this equation, known as the Lambert $\mathrm{W}$ function, due to the nonlinearity in $\beta$. However, this equation can be solved graphically or numerically using methods such as the Newton-Raphson algorithm (Corless et al., 1996).

\subsubsection{Suitability of the formulation}

The $v: p^{\prime}$ relationship (Equation 7) is used to demonstrate the ability of the formulation to describe the four modes (Figure 7). Parameters used for the simulations are given in Table 2. The influence of the parameters $\beta$ (Figure 8 ) and the degradation stress $p_{y}^{\mathrm{II}}$ (Figure 9) is assessed and the case $p_{y}^{\mathrm{I}}=p_{y}^{\mathrm{II}}$ is considered in Figure 10.

Figure 8 shows that it is possible to describe the mode 3. Changing the value of $\beta$ permits to achieve different rates of degradation. In this figure, a non-zero $\Delta e_{c}$ was chosen $\left(\Delta e_{c}>0\right)$, but mode 4 can be achieved by setting $\Delta e_{c}=0$. The influence of $p_{y}^{\mathrm{II}}$ is shown in Figure 9. One can see that this parameter controls the initiation of the process of degradation, and is successful in describing modes 2 and 4 . As previously, modes 1 and 3 can be achieved by setting $\Delta e_{c}=0$. Finally, the case $p_{y}^{\mathrm{I}}=p_{y}^{\mathrm{II}}$ is considered in Figure 10. This case corresponds to an immediate loss of structure at yield. This case does not lead to any instabilities of the formulation. 


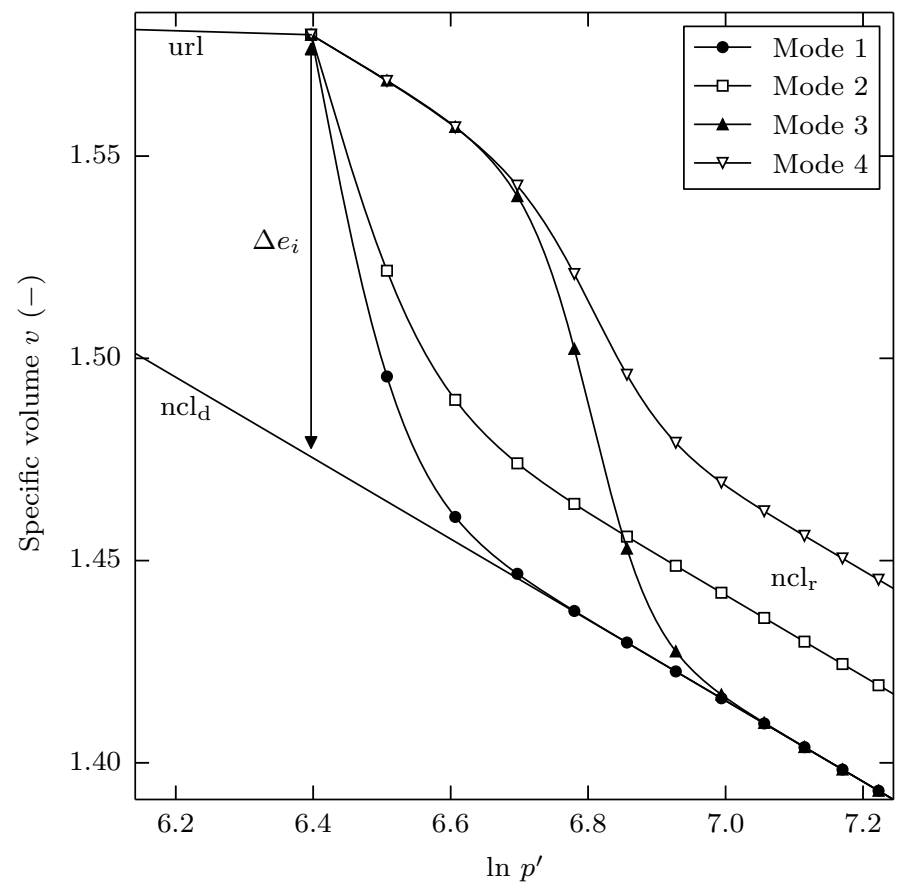

Figure 7: Possibility of the formulation to model the four modes $-\mathrm{ncl}_{d}$ : Normal compression line of the untreated state, url: Unloading-reloading line.

Table 2: Model parameters used for simulations of the four modes in Figure 7

\begin{tabular}{cccccc}
\hline Mode & $p_{y}^{\mathrm{I}}(k P a)$ & $p_{y}^{\mathrm{II}}(k P a)$ & $\Delta e_{i}$ & $\Delta e_{c}$ & $\beta\left(k P a^{-1}\right)$ \\
\hline Mode 1 & 600 & 600 & 0.104 & 0.0 & 0.025 \\
Mode 2 & 600 & 600 & 0.104 & 0.026 & 0.02 \\
Mode 3 & 600 & 900 & 0.104 & 0.0 & 0.025 \\
Mode 4 & 600 & 900 & 0.104 & 0.052 & 0.02 \\
\hline
\end{tabular}




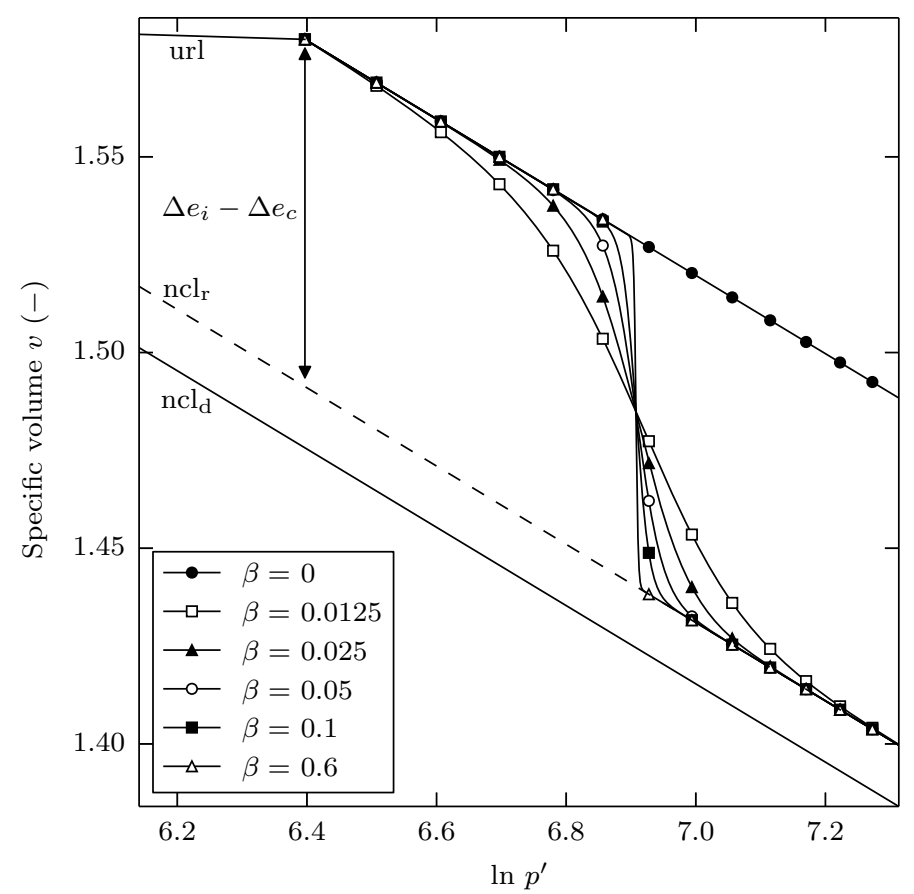

Figure 8: Influence of $\beta: p_{y}^{\mathrm{I}}=600 \mathrm{kPa}, p_{y}^{\mathrm{II}}=1000 \mathrm{kPa}, \Delta e_{c}>0-$ Mode 4 .

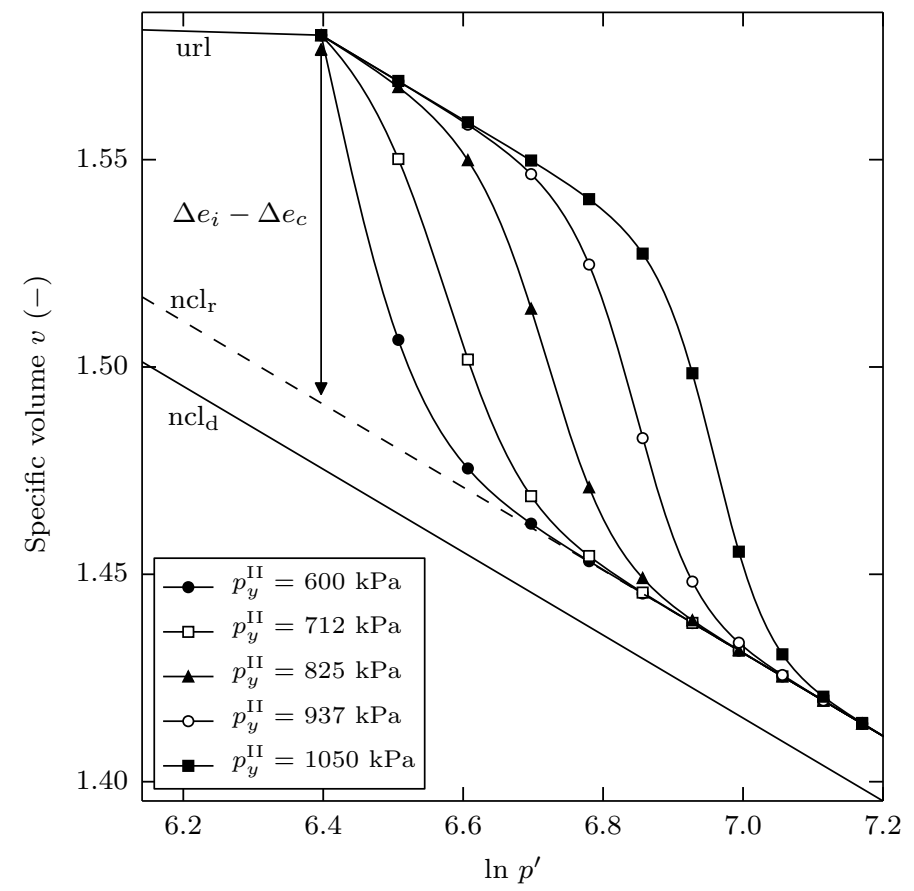

Figure 9: Influence of $p_{y}^{\mathrm{II}}: p_{y}^{\mathrm{I}}=600 \mathrm{kPa}, \beta=0.025, \Delta e_{c}>0-$ Modes 2 and 4 . 


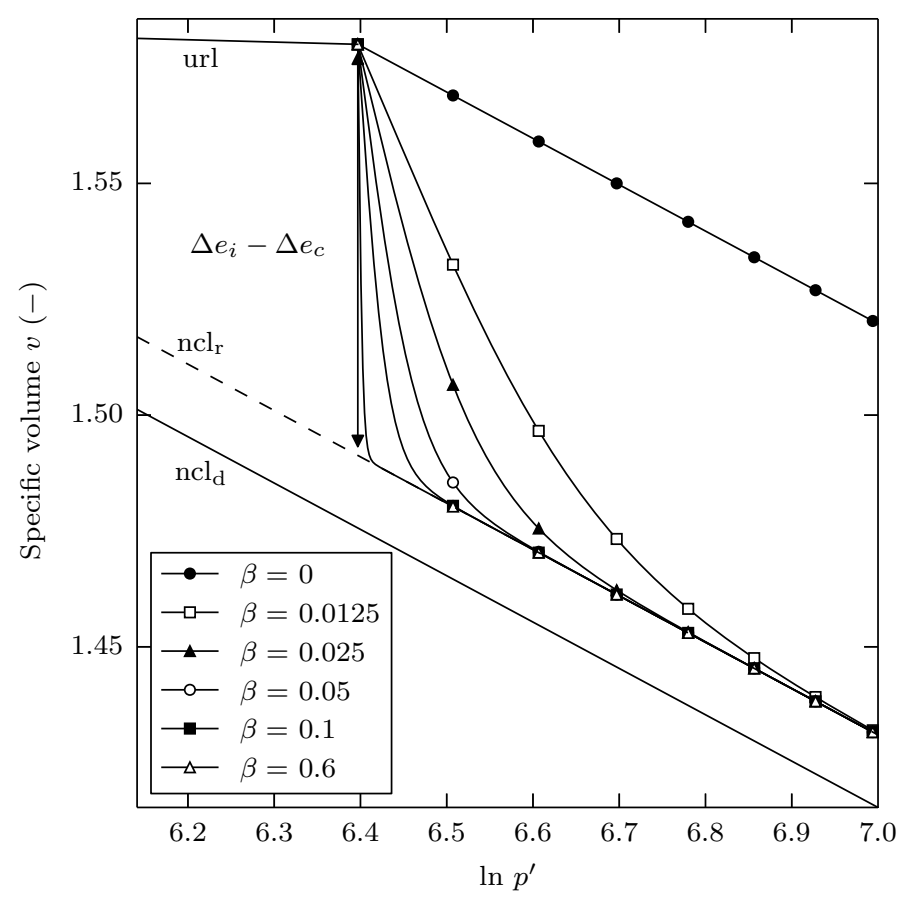

Figure 10: Influence of $\beta: p_{y}^{\mathrm{II}}=p_{y}^{\mathrm{I}}=600 \mathrm{kPa}, \Delta e_{c}>0$ - Mode 2.

\subsection{Yield function $f$}

The addition of lime leads to an increase of the cohesion and the friction angle compared to the untreated soil. Therefore, the equation of the MCC for the yield function $f$ is not sufficient in its original form. One way to account for the increase of cohesion is to consider it as an increase of the tensile strength (e.g. Suebsuk et al. (2010)). This can be modelled by expanding the yield function in the negative stress domain (Figure 11). The parameter $p_{b}(<0)$ is introduced to control the expansion of the yield function due to the increase of the cohesion and is directly obtained from the equation of the CSL. The critical state line does not necessarily pass through the origin anymore. 


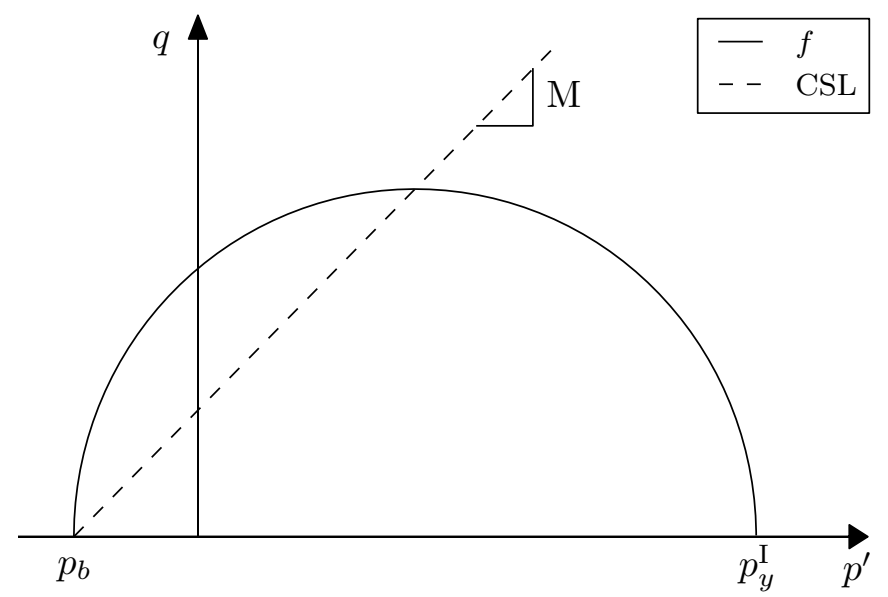

Figure 11: Theoritical yield function for lime treated soils.

The equation chosen for the yield function can therefore be expressed as:

$$
f \equiv q^{2}+\mathrm{M}^{2}\left(p^{\prime}-p_{y}^{\mathrm{I}}\right)\left(p^{\prime}-p_{b}\right) \equiv 0
$$

\subsection{Plastic potential $g$}

The choice of the formulation for the plastic potential $g$ is a major issue in the constitutive modelling of soils. The use of non-associated potentials gives a more accurate description of the real behaviour but comes at the cost of additional parameters with, in most of the cases, no straightforward physical meaning and whose values can rarely be determined from experimental results. This study aims to develop a model based on meaningful parameters determined from classic experimental tests. To this end, always in the framework of the Modified Cam Clay modem, this model assumes that lime treated materials follow an associated flow rule and therefore

$$
g \equiv f \quad \Rightarrow \quad g \equiv q^{2}+\mathrm{M}^{2}\left(p^{\prime}-p_{y}^{\mathrm{I}}\right)\left(p^{\prime}-p_{b}\right)
$$

which leads to the following flow rule for lime treated materials:

$$
\frac{\delta \varepsilon_{p}^{\mathrm{p}}}{\delta \varepsilon_{q}^{\mathrm{p}}}=\frac{\partial g / \partial p^{\prime}}{\partial g / \partial q}=\frac{M^{2}\left(p^{\prime}-p_{b}\right)}{2 p^{\prime} \eta}-\frac{p^{\prime} \eta}{2\left(p^{\prime}-p_{b}\right)}
$$

with $\eta=q / p^{\prime}$. The suitability of this hypothesis will be verified in the Model evaluation section.

\subsection{Summary of the model parameters}

Using the sigmoid equation, a new formulation has been developed to model the degradation of structure at yield for lime treated soils (Equation 7). This formulation has the significant advantage to rely on only 4 additional parameters to the original $\operatorname{MCC}\left(\beta, p_{y}^{\mathrm{II}}, \Delta e_{i}\right.$ and $\left.\Delta e_{c}\right)$, which all have a physical meaning and can all be determined from an isotropic consolidation test performed on the lime treated material. To model 
the influence of the cohesion on the deviatoric behaviour the parameter $p_{b}$, directly related to the equation of the CSL, was introduced. As a conclusion, the following 6 parameters appear to be relevant to account for the effects of a lime treatment on the mechanical behaviour of a material:

$p_{y}^{\mathrm{I}} \quad$ : Primary yield stress

$p_{y}^{\mathrm{II}} \quad$ : Degradation stress

$\Delta e_{i} \quad: \quad$ Additional void ratio at $p_{y}^{\mathrm{I}}$

$\Delta e_{c} \quad: \quad$ Additional void ratio for $p^{\prime} \rightarrow+\infty$

$\beta \quad$ : Rate of degradation

$p_{b} \quad$ : Tensile strength due to the increase of the cohesion

\section{Stress-strain relationship}

\subsection{Elastic behaviour}

It is assumed that only elastic deformation occurs for stress states lying within the yield surface. According to the Modified Cam Clay model, the elastic volumetric increments are given by

$$
\begin{gathered}
\delta \varepsilon_{p}^{\mathrm{e}}=\kappa \frac{\delta p^{\prime}}{v p^{\prime}} \\
\delta \varepsilon_{q}^{\mathrm{e}}=\frac{\delta q}{3 G}
\end{gathered}
$$

with $G$ the shear modulus. As recommended by several authors (e.g. Liu and Carter (2002); Muir Wood (2004)), Poisson's ratio $\nu$ is assumed constant in this model, although it is known to lead to thermodynamic discrepancies under cyclic loading (Zytynski et al., 1978).

\subsection{Plastic behaviour}

\subsubsection{Compliance matrix for hardening case}

The general plastic stress:strain relationship is given by

$$
\left[\begin{array}{c}
\delta \varepsilon_{p}^{\mathrm{p}} \\
\delta \varepsilon_{q}^{\mathrm{p}}
\end{array}\right]=\frac{-1}{\left[\frac{\partial f}{\partial p_{0}^{\prime}}\left[\frac{\partial p_{0}^{\prime}}{\partial \varepsilon_{p}^{\mathrm{p}}} \frac{\partial g}{\partial p^{\prime}}+\frac{\partial p_{0}^{\prime}}{\partial \varepsilon_{q}^{\mathrm{p}}} \frac{\partial g}{\partial q}\right]\right]}\left[\begin{array}{ll}
\frac{\partial f}{\partial p^{\prime}} \frac{\partial g}{\partial p^{\prime}} & \frac{\partial f}{\partial q} \frac{\partial g}{\partial p^{\prime}} \\
\frac{\partial f}{\partial p^{\prime}} \frac{\partial g}{\partial q} & \frac{\partial f}{\partial q} \frac{\partial g}{\partial q}
\end{array}\right] \cdot\left[\begin{array}{l}
\delta p^{\prime} \\
\delta q
\end{array}\right]
$$

The new formulation of the $v: p^{\prime}$ relationship given by Equation (7) is now used as the new hardening rule. For the sake of simplicity, it was assumed that hardening is only controlled by the plastic volumetric strains $\left(f\left(\boldsymbol{\sigma}, \varepsilon_{p}^{\mathrm{p}}\right)\right)$. The volumetric plastic strains for lime treated soils is therefore expressed as 


$$
\delta \varepsilon_{p}^{\mathrm{p}}=\left[\left(\frac{M^{2}\left(2 p^{\prime}-p_{0}^{\prime}-p_{b}\right)+6 q}{M^{2}\left(p^{\prime}-p_{b}\right)}\right)\left(\frac{\partial p_{0}^{\prime}}{\partial \varepsilon_{p}^{\mathrm{p}}}\right)^{-1}\right] \cdot \delta p^{\prime}
$$

and the deviatoric plastic strains can be calculated using the flow rule:

$$
\delta \varepsilon_{q}^{\mathrm{p}}=\left[\frac{M^{2}\left(p^{\prime}-p_{b}\right)}{2 p^{\prime} \eta}-\frac{p^{\prime} \eta}{2\left(p^{\prime}-p_{b}\right)}\right]^{-1} \cdot \delta \varepsilon_{p}^{\mathrm{p}}
$$

\subsubsection{Compliance matrix for softening case}

Lime treated specimens experiencing softening at shear show a maximum rate of dilatation after the peak due to the degradation of the structure. The modelling of these features without introducing additional parameters is a delicate issue. The Structure Cam Clay model (Liu and Carter, 2002) has a formulation for the softening case, but which can lead to contraction of the material at softening. More recently Yang et al. (2014) have proposed a simple formulation based on the SCCM, but although promising does not lead to accurate predictions of the behaviour.

If Equation (5) is used to model the softening behaviour on ]0, $p_{y}^{\mathrm{I}}$ ], the formulation leads to $\Delta e \geq \Delta e_{i}$ and no degradation of the structure is modelled. To model the softening behaviour, we propose a new softening rule in the same framework as the one chosen for the hardening case, where the degradation of the structure is described by the sigmoid equation. To avoid the addition of meaningless parameters, an automatic procedure is proposed based on experimental considerations.

Since $\Delta e_{c}$ arises from the lime treatment and modifies the texture of the soil, it is assumed that the material converges toward the same $\mathrm{ncl}_{\mathrm{r}}$ as under isotropic loading. Based on experimental observations (Robin et al., 2014a) the inflexion point, called $p_{y, s}^{\mathrm{II}}$, was chosen as the intersection of the url and the ncl $\mathrm{r}_{\mathrm{r}}$ (Figure 12) and is given by

$$
p_{y, s}^{\mathrm{II}}=\exp \left(\frac{N_{\lambda}-N_{\kappa}+\Delta e_{c}}{\lambda-\kappa}\right)
$$

which does not require any additional parameter. This leads to the following expression of the softening rule:

$$
\left.\left.\forall p^{\prime} \in\right] 0, p_{y}^{\mathrm{I}}\right] \quad v_{s}\left(p^{\prime}\right)=N_{\lambda}-\lambda \ln \left(p^{\prime}\right)+\left(\Delta e_{i}-\Delta e_{c}\right) \cdot\left[\frac{e^{-\beta_{s} p_{y}^{\mathrm{I}}}+e^{-\beta_{s} p_{y, s}^{\mathrm{II}}}}{e^{-\beta_{s} p^{\prime}}+e^{-\beta_{s} p_{y, s}^{\mathrm{II}}}}\right]+\Delta e_{c}
$$




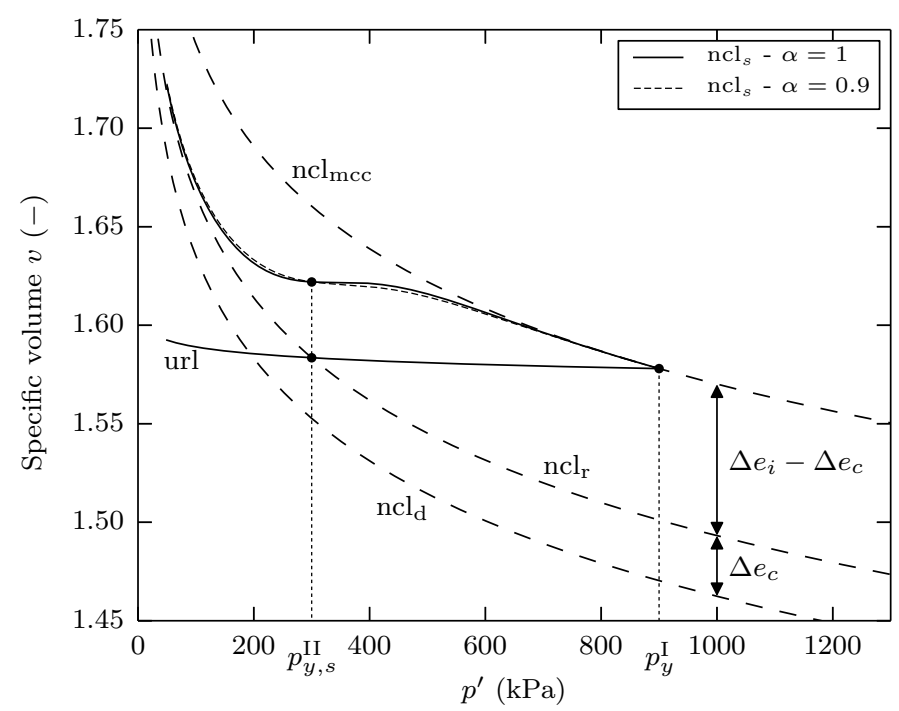

Figure 12: Modelling of the behaviour at yield for softening case.

The parameter $\beta_{s}$ describes the rate of destructuration and is calculated automatically. During the post-yield behaviour, the maximum rate of dilation is observed right after the deviatoric stress reaches its maximum. This is due to the structure experiencing an extensive degradation. Such feature can be modelled by using as $\beta_{s}$, the maximum rate of degradation $\beta_{0}$, leading to $v_{s}$ monotonically decreasing (not strictly). In this case, the first derivative being zero only for a single effective mean stress (which is not necessarily $p_{y, s}^{\mathrm{II}}$ ). This method presents the advantage that $\beta_{0}$ can easily be determined graphically or numerically. However, for consistency and numerical stability, $v_{s}$ is preferred to be strictly monotonic decreasing on $\left.] 0, p_{y}^{\mathrm{I}}\right]$. For this purpose, we introduced a constant $\alpha$ such that

$$
\beta_{s}=\alpha \times \beta_{0}
$$

the bijection (one-to-one correspondence) being ensured by $\alpha \in] 0,1[$. Practically, $\alpha$ can control the smoothness of the process of destructuration. In this model, $\alpha$ is arbitrarily set to 0.9 , which ensures a bijective function and an appropriate rate of degradation at yield (Figure 12).

This two-step method is the simplest and most reliable way to calculate $\beta_{s}$, simply because the determination of $\beta_{0}$ is independent of the stress state and does not require information about the gradient at $p_{y, s}^{\mathrm{II}}$, which can not be determined from experimental results, and may lead to numerical instabilities. The suitability of this method will be demonstrated during the Model evaluation section.

The strain-strain relationship for the softening case is obtained by introducing Equation 18 into Equation 14. Such softening rule respects the associated potential hypothesis. 


\section{Model evaluation}

The robustness of the model for lime treated soils (MLTS) is assessed in predicting the behaviour of artificially and naturally structured materials under isotropic loading and drained paths for different confining pressures. As a first step, we assess the suitability of an associated flow rule for the modelling of lime treated soils using the experimental results from Robin et al. (2014a). Then, the model is used to predict the behaviour of silt specimens treated with different lime contents $(0.5 \%, 1 \%, 2 \%$, and $5 \%$ CaO) (Robin et al., 2014a). The model is finally tried out on naturally structured specimens of calcarenite (Lagioia and Nova, 1995). For both cases, the additional parameters to the Modified Cam Clay were determined from a single isotropic compression test performed on the structured specimens (Table 3).

Table 3: Values of the model parameters

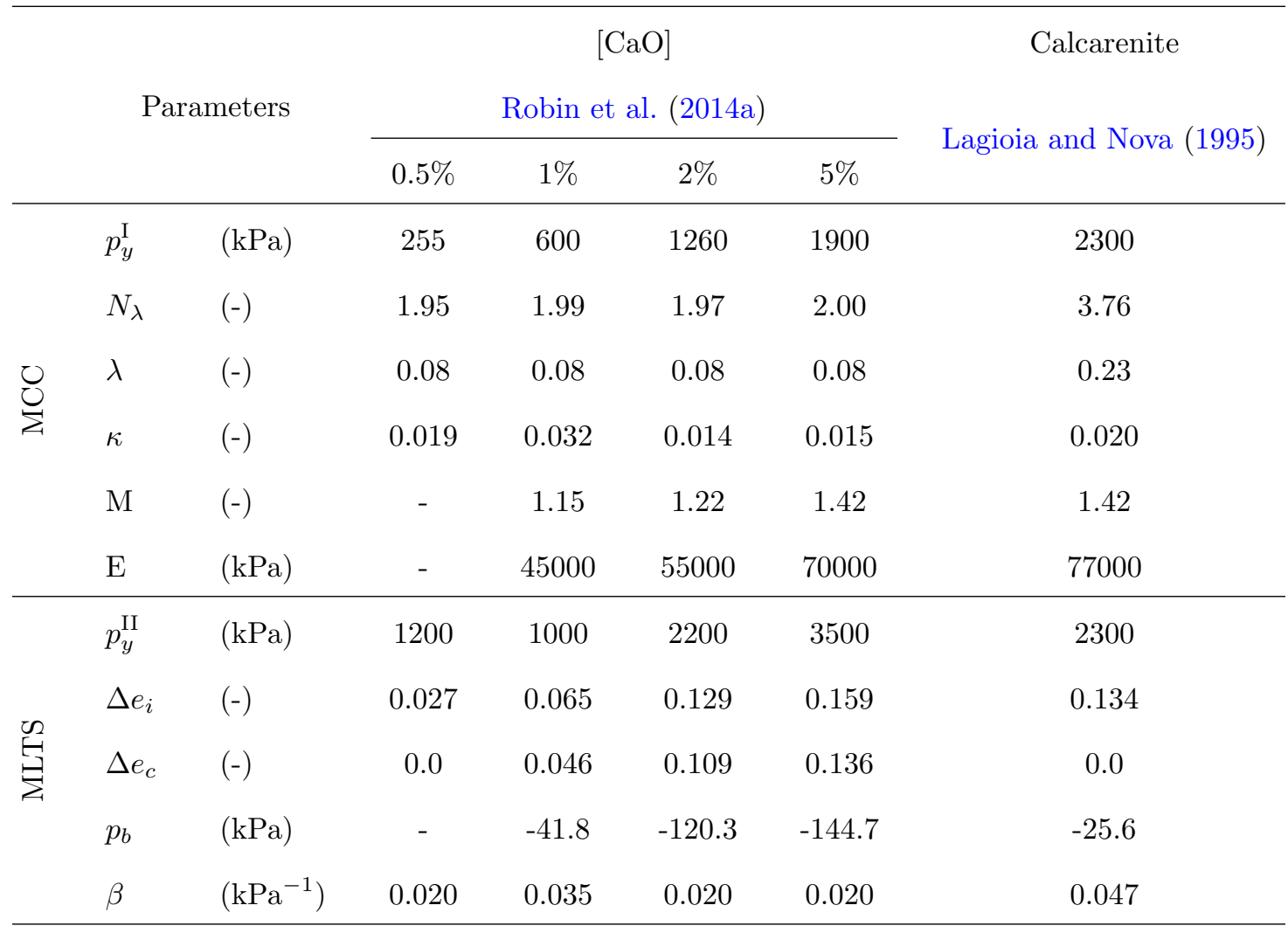

MCC: Modified Cam Clay model, MLTS: Model for Lime Treated Soils.

\subsection{Associated flow rule hypothesis}

In this section, we assess the validity of an associated flow rule for lime treated soils. Plastic strain increment vectors from drained triaxial tests performed on specimens treated with $1 \%, 2 \%$, and $5 \%$ in lime were determined. The yield loci values were normalized with respect to the primary yield stress $p_{y}^{\mathrm{I}}$. 
Figure 13 shows that it seems reasonable to assume that plastic strain increment vectors are normal to the yield surface. The hypothesis of an associated flow rule for the modelling of lime treated soils appears therefore suitable.

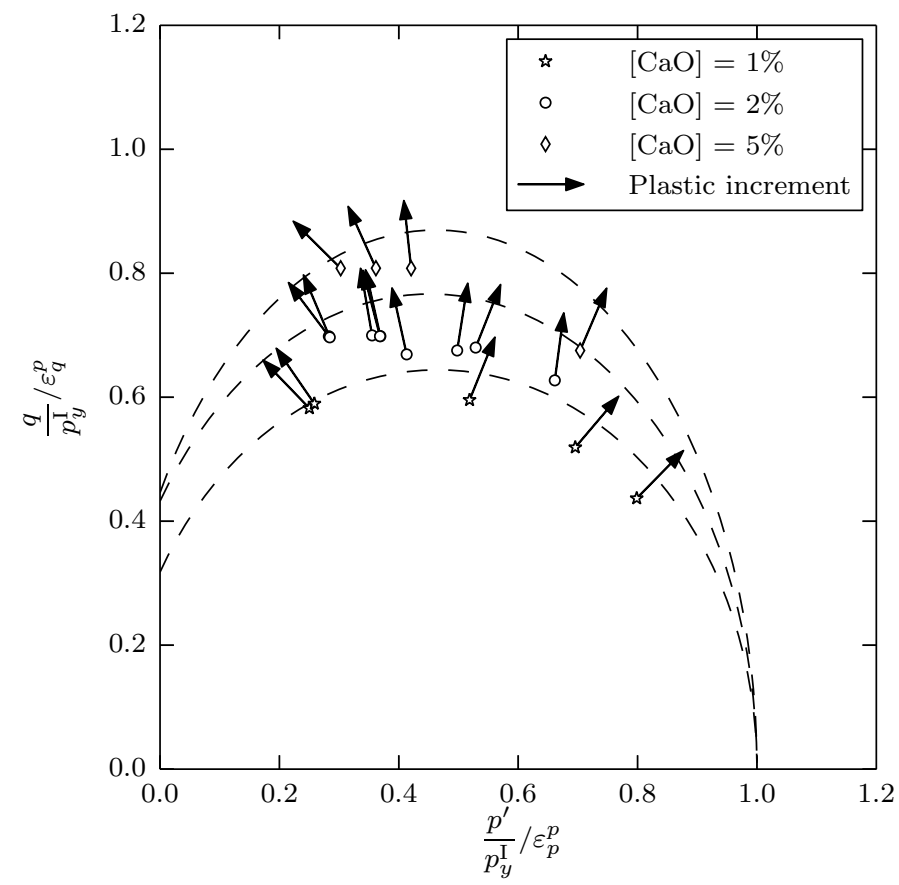

Figure 13: Vectors of plastic strain increment plotted at yield points obtained from drained triaxial tests on lime treated specimens.

\subsection{Lime treated specimens}

\subsubsection{Isotropic consolidation}

The new formulation to model the degradation of the structure at yield (Equation 7) was applied on lime treated specimens. Two sets of experimental results of isotropic compressions tests were used to verify the general nature of the formulation. The first set was treated with $0.5 \% \mathrm{CaO}$ and follows the mode 3 $\left(\Delta e_{c}=0\right)$, and the second with $1 \% \mathrm{CaO}$ and follows the mode $4\left(\Delta e_{c}>0\right)$ (Figure 14). For the two sets the parameter $\beta$ was determined from the gradient of the curve at $p^{\prime}=p_{y}^{\mathrm{II}}$ using the Newton-Raphson algorithm.

The use of the sigmoid equation appears very appropriate to model the degradation experienced at yield by lime treated materials. For both concentrations in lime, there is a very good agreement between the experimental results and the model. The degradation is initiated at the right effective mean stress and with the correct rate, and both sets converge toward the correct normal compression line. 


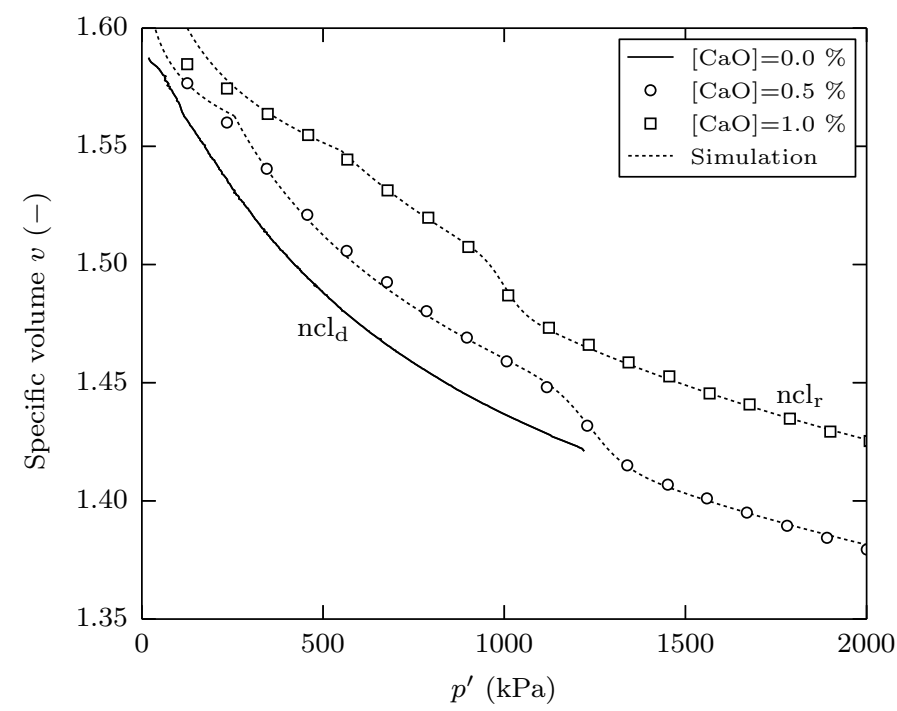

Figure 14: Validation of the formulation on $0.5 \%$ and $1 \%$ lime treated specimens - ncl $_{\mathrm{d}}$ : normal compression line of the untreated state, $\mathrm{ncl}_{\mathrm{r}}$ : normal compression line of the residual state.

\subsubsection{Shear behaviour}

No additional parameters to the MCC are required by this model to describe the degradation of the structure at shear apart from $p_{b}$ that is derived from the equation of the CSL. The model was applied on lime treated specimens along different drained stress paths and confining pressures (Figures 15-17). Three concentrations in lime were tested to consider various degrees of structure: $1 \%, 2 \%$ and $5 \% \mathrm{CaO}$.

The yield loci and the convergence toward the critical state appear satisfactory modelled for all the lime contents tested. They confirm the appropriateness of the equation of the yield function $f$ and the suitability of the parameter $p_{b}$ to account for the influence of the lime treatment on the cohesion and the critical state.

For both hardening and softening cases, the volumetric deformations are very accurately predicted by the model. This supports the assumption of the volumetric deformations being mostly controlled by the structure. The evolution of the specific volume for the softening case is particularly accurate (Figure 18). The model is successful to reproduce the dilation post-yield of the specimens and the maximum rate of dilation after the deviatoric stress peak, which is one of the key features of structured soils.

The framework chosen for the softening case appears suitable and very powerful. The assumptions made to calculate automatically in the background the parameters $p_{y, s}^{\mathrm{II}}$ and $\beta_{s}$ (Figure 12) are therefore relevant and successful to reproduce the majority of the main features of behaviour of lime treated soils, and that using only information from isotropic test results. It also ensures that the material experiences dilation at yield for samples in the dry side.

The MLTS appears very satisfactory to model the key features of lime treated soils considering the limited number of parameters and the straightforwardness of their determination. Nevertheless, the model 
tends to deviate from the experimental results during the post-yield stage before converging back toward the critical state at high axial strains for some samples subjected to a high preconsolidation pressure (600 $\mathrm{kPa}$ in Figure 15, $900 \mathrm{kPa}$ in Figure 16). In this model, potentials $f$ and $g$ are associated and hardening is controlled by the plastic volumetric deformations $\varepsilon_{p}^{\mathrm{p}}$ only $\left(f\left(\boldsymbol{\sigma}, \varepsilon_{p}^{\mathrm{p}}\right)\right)$. This has for consequences to reflect the degradation of the structure on the deviatoric stress. However, lime treated specimens experiencing hardening do not show any sign of this phenomenon for any of the concentrations tested. This might come from the fact that the contribution of $\varepsilon_{q}^{\mathrm{p}}$ was neglected in this model, and/or that the 'amount' of structure is too low to significantly affect the stresses.

For samples in the dry side, the model predicts larger values for the yield loci than what is experimentally observed. One of the known limitations of the MCC is that it overestimates the values in such situation; the fact that we extended the yield function in the tensile domain with $p_{b}$ amplifies this feature. 

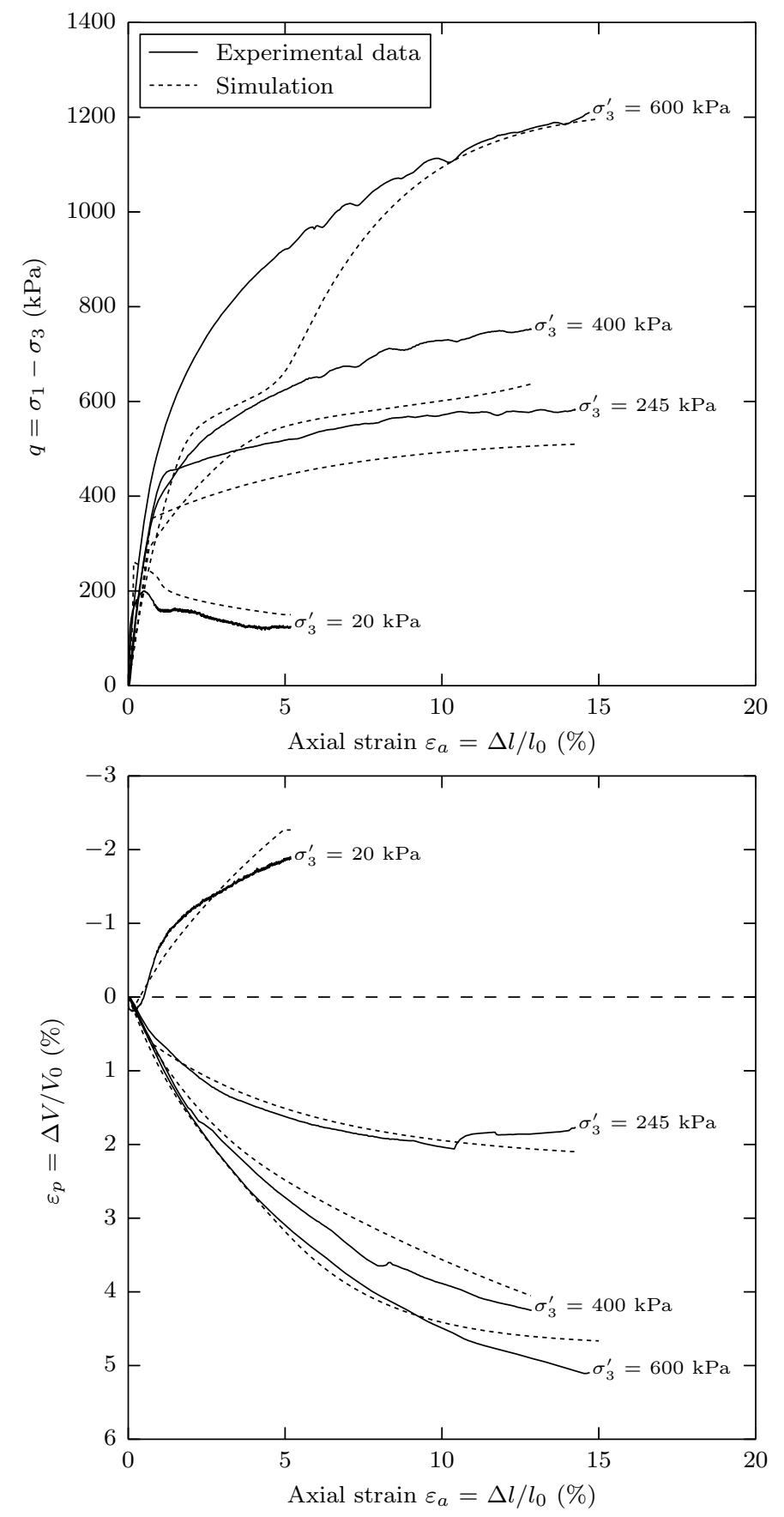

Figure 15: Comparison between experimental results and the model of drained triaxial tests performed on lime treated specimens with $1 \% \mathrm{CaO}$ (Robin et al., 2014a). 

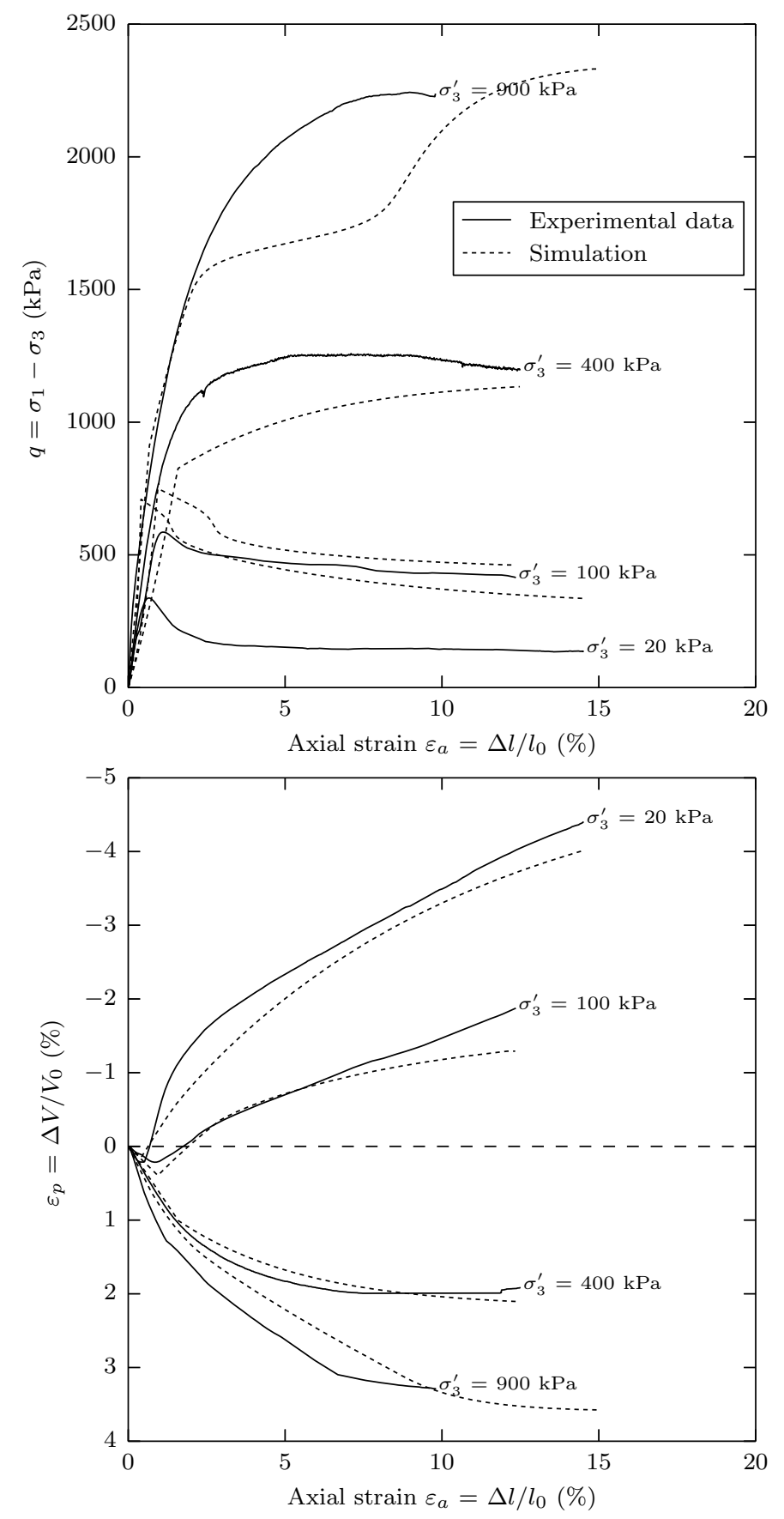

Figure 16: Comparison between experimental results and the model of drained triaxial tests performed on lime treated specimens with $2 \% \mathrm{CaO}$ (Robin et al., 2014a). 

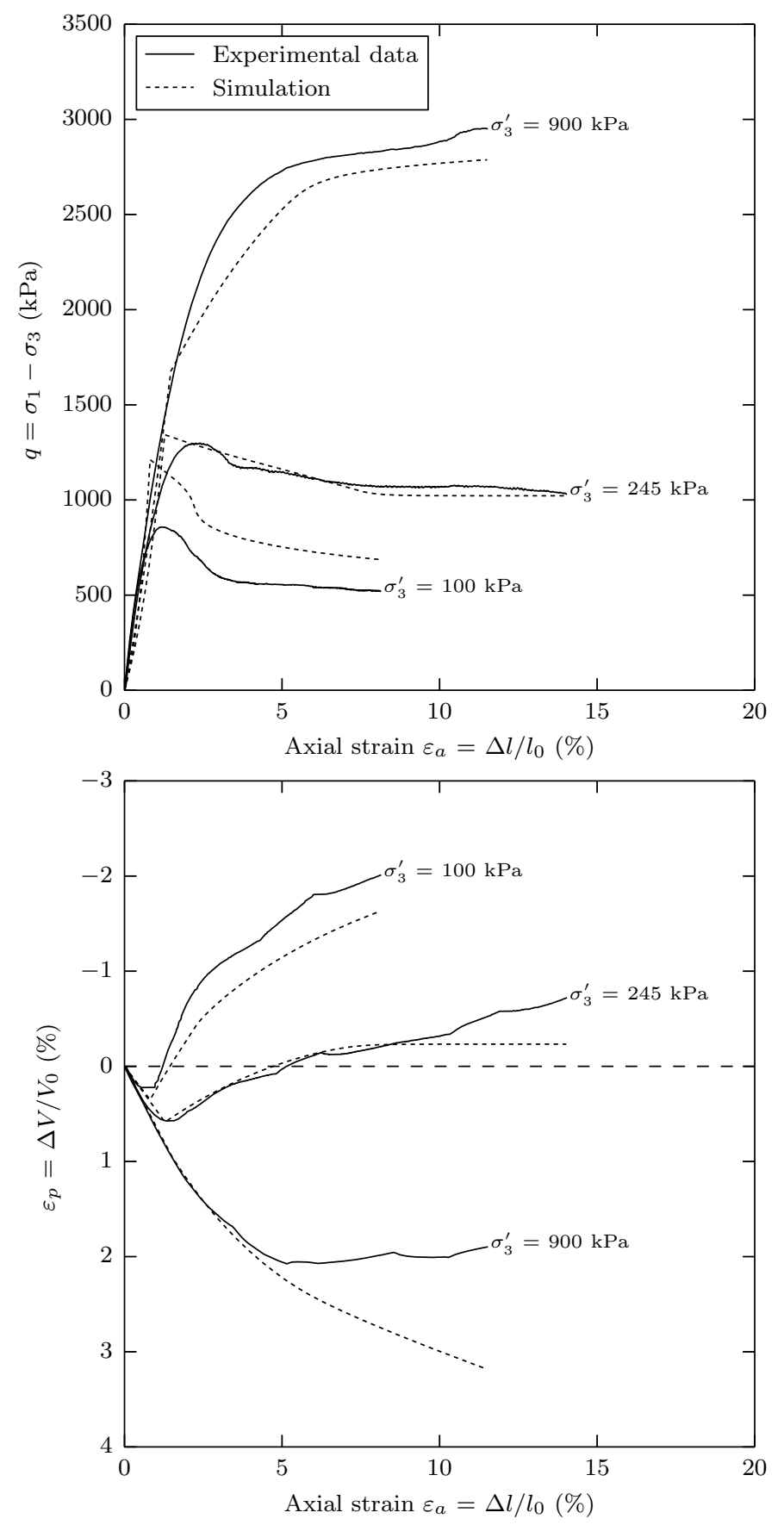

Figure 17: Comparison between experimental results and the model of drained triaxial tests performed on lime treated specimens with 5\% CaO (Robin et al., 2014a). 


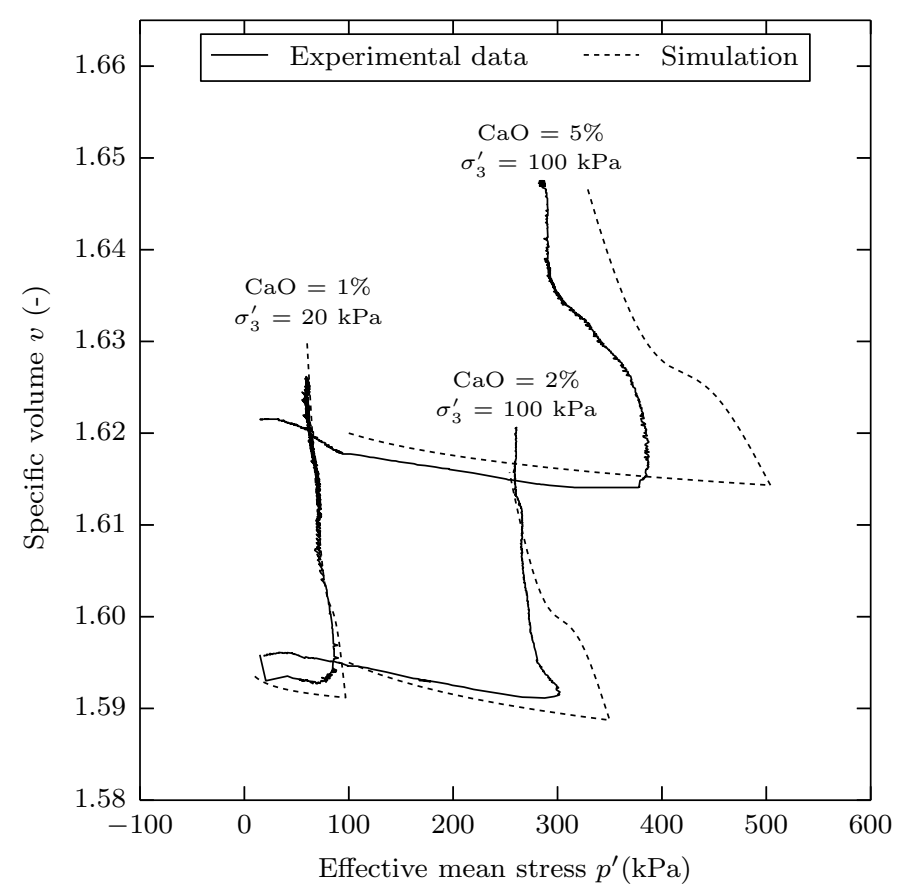

Figure 18: Comparison between drained triaxial results and the model of the specific volume for different lime contents (Robin et al., 2014a).

\subsection{Naturally structured soils}

Although the formulation was originally designed for lime treated soils, there are several common features of behaviour between artificially and naturally materials that could also make it suitable for the latter.

\subsubsection{Isotropic consolidation}

The suitability of the formulation to model the degradation of naturally structured soils under isotropic loading is verified using the results from Lagioia and Nova (1995) on natural calcarenite (Figure 19). Likewise the lime treated specimens, calcarenite experiences a degradation of the structure at yield but that occurs immediately at yield $\left(p_{y}^{\mathrm{I}}=p_{y}^{\mathrm{II}}\right)$ and at a very high rate. Again, $\beta$ was solved numerically using the NewtonRaphson procedure. There is no information about the behaviour of the destructured calcarenite under isotropic loading, and therefore no information is given about the value of the residual void ratio $\Delta e_{c}$. However, Lagioia and Nova (1995) considered that calcarenite converges toward the ncl of the destructured state. Thus, it is assumed that calcarenite has no residual void ratio $\left(\Delta e_{c}=0\right)$ and follows the mode 1 . The parameters used for the simulations are given in Table 3.

Though the origin of the cementation is different, the MLTS appears suitable to model naturally structured materials under isotropic loading. As for the lime treated specimens, the degradation is initiated at the right effective mean stress and at the correct rate till it reaches the normal compression line of the destructured state. 


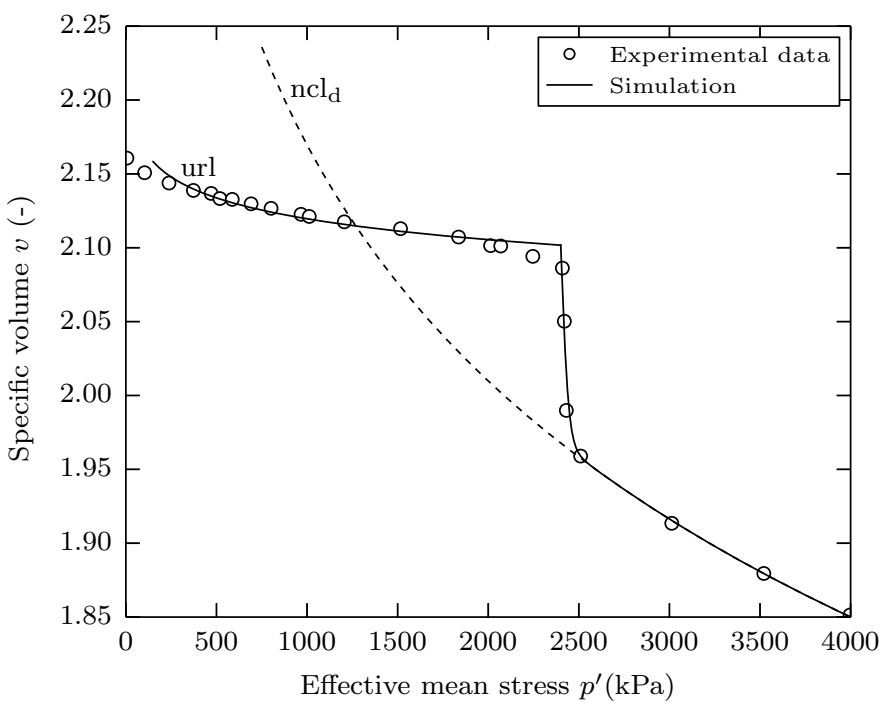

Figure 19: Validation of the formulation on natural calcarenite (after Lagioia and Nova (1995)) - ncl: normal compression line.

\subsubsection{Shear behaviour}

The model is now tried to reproduce the behaviour of samples naturally structured calcarenite at shear submitted to drained triaxial tests. The parameter $p_{b}$ was determined from the equation of CSL given in Lagioia and Nova (1995).

For samples of calcarenite experiencing hardening (Figure 20) the MLTS gives a very good agreement with the experimental results of the yield loci and the convergence toward the critical state. At yield, the degradation of the structure seems to affect the deviatoric stress, which is successfully described by model. The specific volume at yield (Figure 21) is accurately modelled and the trends of the volumetric deformations (Figure 20) are satisfactory, although the values appear underestimated at large deformations.

For samples experiencing softening (Figure 22) the MLTS gives an accurate prediction of the yield loci and the convergence toward the critical state. However, samples revealed an unusual behaviour in the framework of the MCC and the critical state theory regarding the volumetric deformations. It is generally accepted that for the softening case samples experience dilation at yield. However, the calcarenite seems to behave differently and keeps contracting at yield, although the deviatoric stress decreases. 

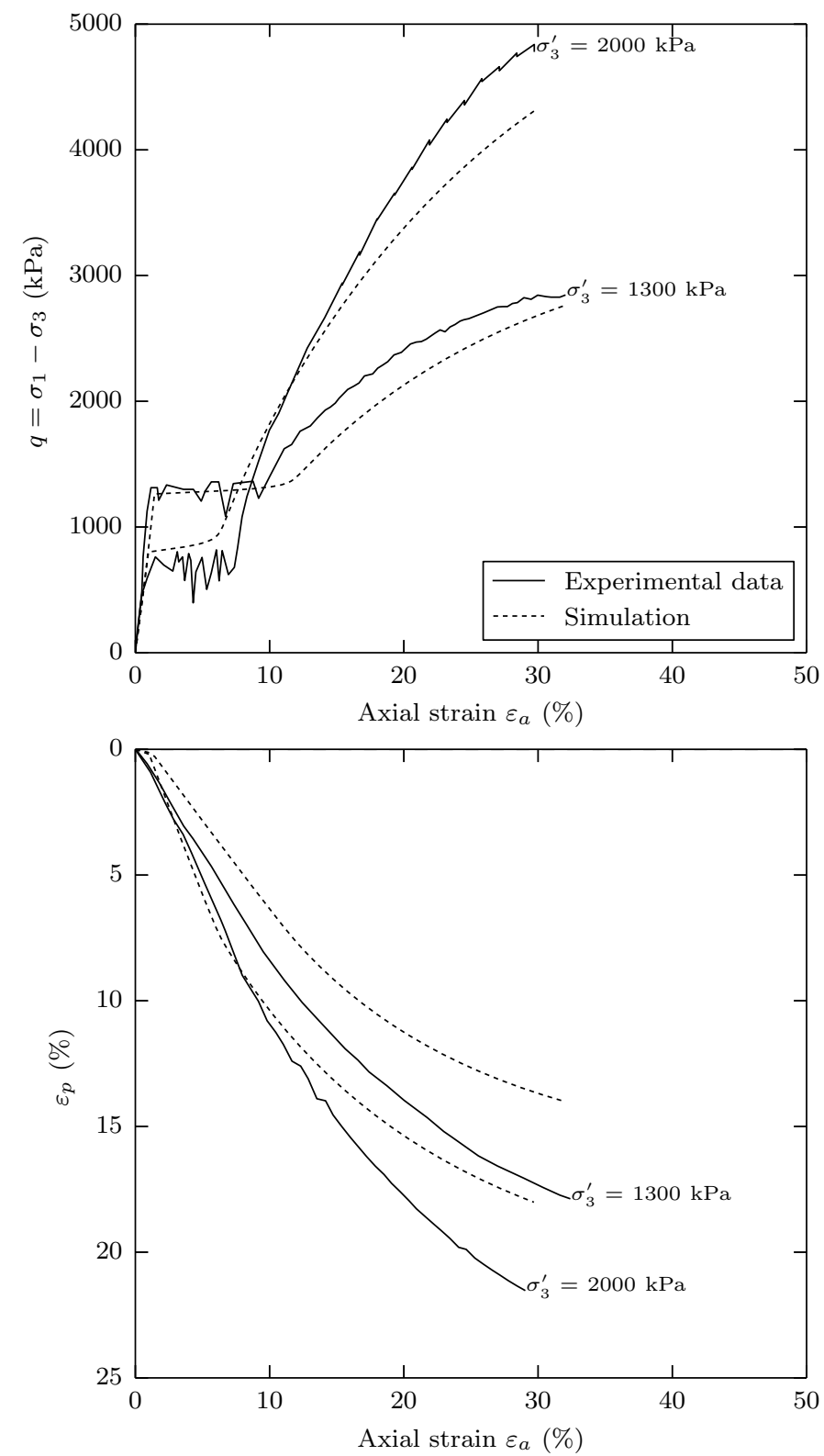

Figure 20: Comparison between experimental results and the model of drained triaxial tests performed on calcarenite and experiencing hardening (Lagioia and Nova, 1995). 


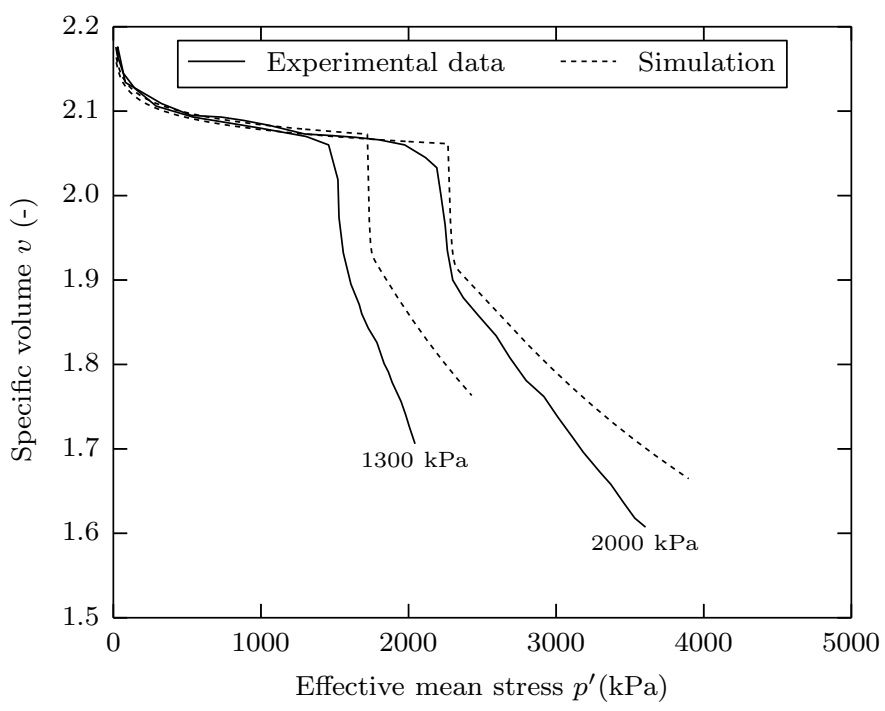

Figure 21: Comparison between the experimental results and the model for the specific volume (Lagioia and Nova, 1995) 

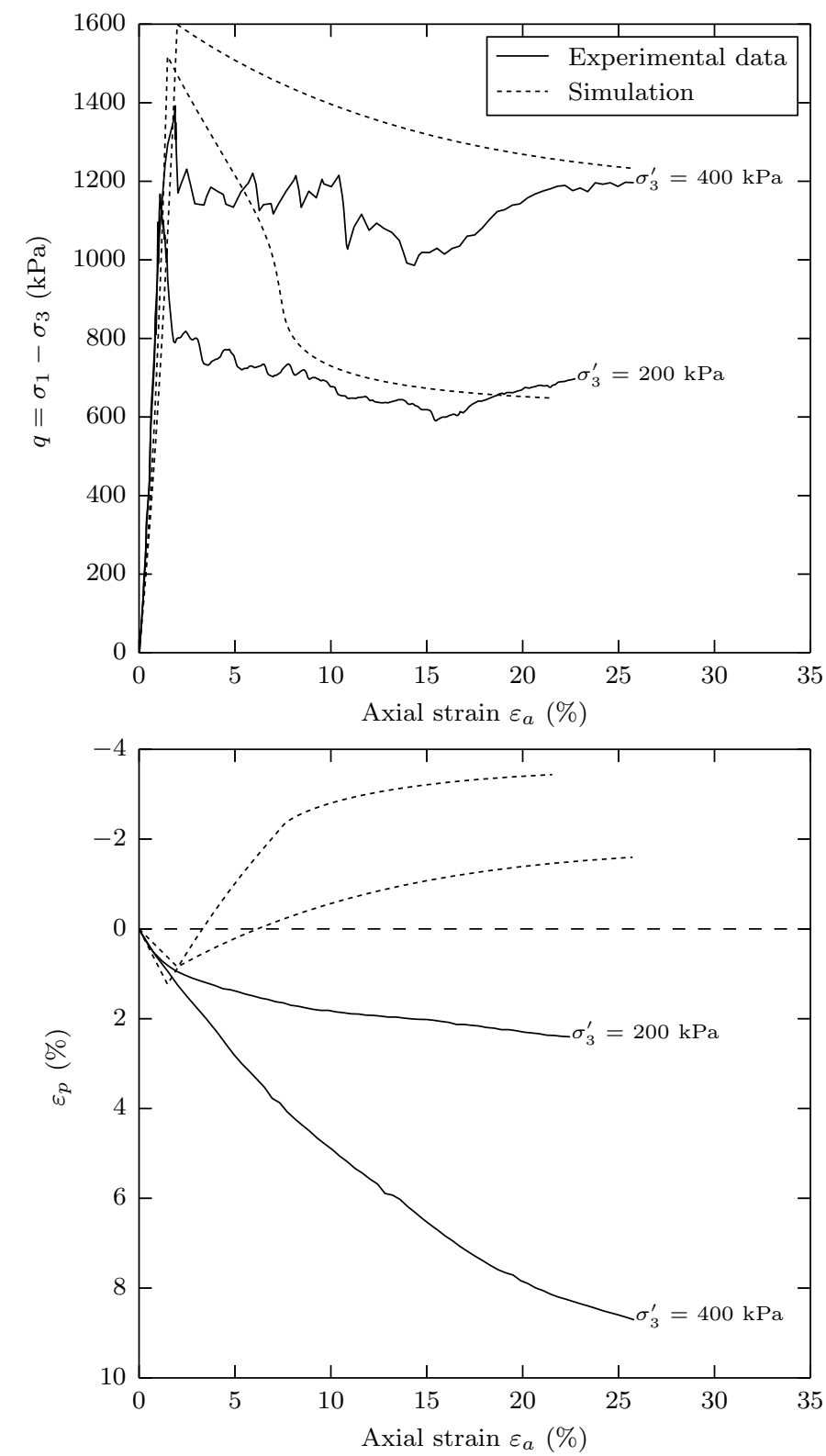

Figure 22: Comparison between experimental results and the model of drained triaxial tests performed on calcarenite and experiencing sofening (Lagioia and Nova, 1995). 


\subsection{Discussion: influence of the initial void ratio on the degradation mode}

The MLTS can successfully reproduce a large number of features of both lime treated soils and naturally structured soils. However, the model deviates from the experimental results for 1) lime treated specimens subjected to high preconsolidation pressures experiencing hardening, and 2) samples of calcarenite experiencing softening. In this section, we propose a hypothesis to explain these limitations using the initial void ratio of the material.

During the early post-yield stage, the degradation of the structure seems to affect the stress:strain response for samples of calcarenite experiencing hardening, but not for the lime treated specimens. Furthermore, for the softening case, lime treated specimens experience dilation, as predicted by the critical state theory, but this is not the case for the samples of calcarenite, which experience contraction despite the decrease of deviatoric stress at yield.

For the calcarenite, the initial additional void ratio at yield $\Delta e_{i}$ and the range of stresses are similar to those measured on lime treated soils with $5 \% \mathrm{CaO}$. The only difference between the two materials lies in the initial specific volume (around 1.6 for the lime treated specimens and 2.2 for the calcarenite). When the calcarenite starts yielding, the structure is rapidly degraded due to the brittleness of the material. Lagioia and Nova (1995) stated that some softening could take place under isotropic loading, and explained that the plateau of the deviatoric stress is associated with debonding. However, what was interpreted as softening under isotropic loading is more likely to be collapse since the specific volume decreases during the destructuration. Once the particles are released from the cementation, they immediately collapse and start filling the voids as the axial deformation increases. During this stage, there is no effective friction inside the material and therefore no additional deviatoric stress is necessary to increase the axial deformation. The effective friction is restored once the particles are close enough and the porosity is significantly reduced, which leads to an increase of the deviatoric stress followed by convergence toward the critical state. This mechanism also explains why samples experiencing softening do not have a dilatant behaviour at yield as predicted by the critical state theory. The dilation process is the direct result of the interlocking of the particles; in the case of the calcarenite, the fast degradation of the structure leads to the collapsing of the particles and therefore to the contraction of the sample. Although the deviatoric stress decreases at yield, since there is no interlocking of the particles, there is no dilation of the sample.

For the lime treated specimens of this study, the initial conditions were chosen to match those used on-site and obtained from the Proctor compaction test (Robin et al., 2014a). In these conditions, the void ratio is too low to generate a noticeable collapse in the material, and the destructuration is a slower process. The degradation of the structure takes place but particles are already in contact, which maintains a friction between them and leads to increase in the deviatoric stress with the axial deformation. Therefore, the degradation of the structure is not observed directly on the stress:strain response. If the conditions imply strain softening, interlocking happens and therefore dilation, which is observed on the experimental results 
and properly reproduced by the MLTS.

In light of these observations, it appears that the initial void ratio has a higher impact on the behaviour of the material than the degree and the origin of cementation. As matter of fact, the mode of degradation of a large number of structured materials seems to be closely related to the initial void ratio (Table 4). Further work must be carried out to identify the parameters responsible for the different behaviours. Nevertheless, the MLTS appears to reproduce the main features of behaviour of lime treated soils, and is also successful in modelling the main trends that are observed in naturally structured soils.

Table 4: Correlation between the initial void ratio and the mode of degradation

\begin{tabular}{lllll}
\hline & Origin of & Material & $v_{i}(-)$ & Study \\
& structure & & & \\
Mode 1 & Natural & Pisa clay & 2.8 & Callisto and Calabresi (1998) \\
& Artificial & St-Alban clay & 6.0 & Tremblay et al. (2001) \\
\hline Mode 2 & Natural & Louiseville clay & 3.0 & Lapierre et al. (1990) \\
& Artificial & Louiseville clay & $\gg 3$ & Tremblay et al. (2001) \\
\hline Mode 3 & Natural & Corinth marl & 1.6 & Anagnostopoulos et al. (1991) \\
& Artificial & Silt & 1.6 & Robin et al. (2014a) \\
\hline Mode 4 & Natural & Vallericca clay & 1.8 & Callisto and Rampello (2004) \\
& Artificial & Sandstone & $<1.6$ & Rotta et al. (2003) \\
\hline
\end{tabular}

$v_{i}$ : initial specific volume.

\section{Conclusion}

A new model in the framework of the Modified Cam Clay model was developed for lime treated soils. In order to introduce only relevant parameters, the most important features of lime treated materials and naturally structured soils that should be reproduced by a model were identified. Experimental results reveal that both naturally and artificially cemented soils have a very similar mechanical behaviour at yield.

To account for the effects of structure on the behaviour of soils, a new formulation was developed based on Richards's equation. Only 4 new additional parameters to the MCC were introduced: the degradation stress $p_{y}^{\mathrm{II}}$, the rate of degradation $\beta$, the additional void ratio at $p_{y}^{\mathrm{I}}$, and the additional void ratio $\Delta e_{c}$ at $p^{\prime} \rightarrow+\infty$. The power of this model is that all the additional parameters have a physical meaning and can be determined from a single isotropic consolidation test performed on the structured material. A transparent 


\section{Appendix A. Notation}

\section{Symbol Definition}

CSL Critical State Line

E Young's modulus

$f \quad$ yield function

$g \quad$ plastic potential

G shear modulus

M slope of critical state line

MCC Modified Cam Clay Model

MLTS Model for Lime Treated Soils

ncl normal compression line

$\mathrm{ncl}_{\mathrm{d}} \quad$ normal compression line of the destructured state

$\mathrm{ncl}_{\mathrm{r}} \quad$ normal compression line of the residual state 


\section{Symbol Definition}

ncl $_{\text {mcc }}$ normal compression line of modified Cam Clay model

$N_{\lambda} \quad$ specific volume at $p^{\prime}=1 \mathrm{kPa}$

$p^{\prime} \quad$ effective mean stress

$p_{b} \quad$ tensile stress

$p_{y}^{\mathrm{I}} \quad$ primary yield stress

$p_{y}^{\mathrm{II}} \quad$ degradation stress

$p_{y, s}^{\mathrm{II}} \quad$ degradation stress for softening case

$q \quad$ deviatoric stress

url unloading-reloading line

$v \quad$ specific volume

$v_{s} \quad$ specific volume for the structured soil

$\alpha \quad$ parameter of bijection for softening case

$\beta \quad$ rate of degradation

$\beta_{s} \quad$ rate of degradation for softening case

$\beta_{0} \quad$ rate of degradation for monotonic decreasing function $v_{s}$

$\Delta e_{c} \quad$ residual additional void ratio at $p^{\prime} \rightarrow+\infty$

$\Delta e_{i} \quad$ initial additional void ratio at $p^{\prime}=p_{y}^{\mathrm{I}}$

$\varepsilon_{p}, \varepsilon_{p}^{\mathrm{e}}, \varepsilon_{p}^{\mathrm{p}} \quad$ total, elastic, and plastic volumetric strains

$\varepsilon_{q}, \varepsilon_{q}^{\mathrm{e}}, \varepsilon_{q}^{\mathrm{p}} \quad$ total, elastic, and plastic deviatoric strains

$\kappa \quad$ elastic stiffness parameter for changes in effective mean stress

$\lambda \quad$ plastic stiffness parameter for changes in effective mean stress

$\xi \quad$ gradient of the curve $\left(v: p^{\prime}\right)$ at $p^{\prime}=p_{y}^{\mathrm{II}}$

$\sigma_{1}, \sigma_{3} \quad$ axial, radial stress 


\section{References}

Ahnberg, H., 2007. On yield stresses and the influence of curing stresses on stress paths and strength measured in triaxial testing of stabilized soils. Canadian geotechnical journal 44 (1), 54-66.

Anagnostopoulos, a. G., Kalteziotis, N., Tsiambaos, G. K., Kavvadas, M., 1991. Geotechnical properties of the Corinth Canal marls. Geotechnical and Geological Engineering 9 (1), 1-26.

Aversa, S., 1991. Mechanical behaviour of soft rocks: some remarks. In: Proc. of the Workshop on "Experimental characterization and modelling of soils and soft". Vol. 98. pp. 191-223.

Balasubramaniam, A., Buessucesco, B., Oh, Y.-N. E., Bolton, M. W., Bergado, D., Lorenzo, G., 2005. Strength degradation and critical state seeking behaviour of lime treated soft clay. In: International Conference on Deep Mixing-Best Practice and Recent Advances. Vol. 1. Stockholm, pp. 35-40.

Baudet, B., Stallebrass, S., 2004. A constitutive model for structured clays. Géotechnique 54 (4), $269-278$.

Brandl, H., 1981. Alteration of soil parameters by stabilization with lime. In: 10th International Conference on Soil Mechanics and Foundation Engineering. Stockholm, pp. 587-594.

Burland, J. B., 1990. On the compressibility and shear strength of natural clays. Géotechnique 40 (3), 329-378.

Burland, J. B., Rampello, S., Georgiannou, V. N., Calabresi, G., 1996. A laboratory study of the strength of four stiff clays. Géotechnique 46 (3), 491-514.

Callisto, L., Calabresi, G., 1998. Mechanical behaviour of a natural soft clay. Géotechnique 48 (4), $495-513$.

Callisto, L., Rampello, S., 2004. An interpretation of structural degradation for three natural clays. Canadian Geotechnical Journal 41 (3), 392-407.

Consoli, N. C., Lopes, L. d. S., Prietto, P. D. M., Festugato, L., Cruz, R. C., 2011. Variables Controlling Stiffness and Strength of Lime-Stabilized Soils. Journal of Geotechnical and Geoenvironmental Engineering 137 (6), 628-632.

Corless, R. M., Gonnet, G. H., Hare, D. E. G., Jeffrey, D. J., Knuth, D. E., 1996. On the Lambert W Function. Advances in Computational Mathematics 5, 329-359.

Cotecchia, F., Chandler, R. J., 2000. A general framework for the mechanical behaviour of clays. Géotechnique 50 (4), $431-447$.

Cuisinier, O., Auriol, J.-C., Le Borgne, T., Deneele, D., 2011. Microstructure and hydraulic conductivity of a compacted lime-treated soil. Engineering Geology 123 (3), 187-193.

Cuisinier, O., Masrouri, F., Pelletier, M., Villieras, F., Mosser-Ruck, R., 2008. Microstructure of a compacted soil submitted to an alkaline PLUME. Applied Clay Science 40 (1-4), 159-170.

Flora, A., Lirer, S., Amorosi, A., Elia, G., 2006. Experimental observations and theoretical interpretation of the mechanical behaviour of a grouted pyroclastic silty sand. In: Proc. VI European Conference on Numerical Methods in Geotechnical Engineering, NUMGE 06. Graz, Austria.

Gens, A., Nova, R., 1993. Conceptual bases for a constitutive model for bonded soils and weak rocks. Geotechnical engineering of hard soils-soft rocks 1 (1), 485-494.

Horpibulsuk, S., Liu, M. D., Liyanapathirana, D. S., Suebsuk, J., 2010. Behaviour of cemented clay simulated via the theoretical framework of the Structured Cam Clay model. Computers and Geotechnics 37 (1-2), 1-9.

Kavvadas, M., Amorosi, A., 2000. A constitutive model for structured soils. Géotechnique 50 (3), $263-273$.

Lagioia, R., Nova, R., 1995. An experimental and theoretical study of the behaviour of a calcarenite in triaxial compression. Géotechnique 45 (4), 633-648

Lapierre, C., Leroueil, S., Locat, J., 1990. Mercury intrusion and permeability of Louiseville clay. Canadian Geotechnical Journal 27 (6), 761-773.

Leroueil, S., Vaughan, P. R., 1990. The general and congruent effects of structure in natural soils and weak rocks. Géotechnique $40(3), 467-488$.

Little, D. N., 1995. Stabilization of pavement subgrades and base courses with lime. Kendall Hunt Pub Co. 
Liu, M. D., Carter, J. P., 2002. A structured Cam Clay model. Canadian Geotechnical Journal 39 (6), $1313-1332$

Liu, M. D., Carter, J. P., 2003. Volumetric Deformation of Natural Clays. International Journal of Geomechanics 3 (2), $236-252$.

Maccarini, M., 1987. Laboratory studies for a weakly bonded artificial soil. Ph.D. thesis, Imperial College London (University of London).

Malandraki, V., Toll, D. G., 2001. Triaxial Tests on Weakly Bonded Soil with Changes in Stress Path. Journal of Geotechnical and Geoenvironmental Engineering 127 (3), 282-291.

Muir Wood, D., 2004. Geotechnical modelling. Vol. Applied Ge. CRC Press.

Nguyen, L. D., Fatahi, B., Khabbaz, H., 2014. A constitutive model for cemented clays capturing cementation degradation. International Journal of Plasticity 56, 1-18.

Nova, R., Castellanza, R., Tamagnini, C., 2003. A constitutive model for bonded geomaterials subject to mechanical and/or chemical degradation. International journal for numerical and analytical methods in geomechanics 27 (9), 705-732.

Oliveira, P. V., 2013. Effect of Stress Level and Binder Composition on Secondary Compression of an Artificially Stabilized Soil. Journal of Geotechnical and Geoenvironmental Engineering 139 (5), 810-820.

Rampello, S., Callisto, L., 1998. A study on the subsoil of the Tower of Pisa based on results from standard and high-quality samples. Canadian Geotechnical Journal 35 (6), 1074-1092.

Richards, F., 1959. A flexible growth function for empirical use. Journal of experimental Botany 10 (29), 290-300.

Robin, V., Cuisinier, O., Masrouri, F., Javadi, A. A., 2014a. Chemo-mechanical modelling of lime treated soils. Applied Clay Science $95,211-219$.

Robin, V., Javadi, A. A., Cuisinier, O., Masrouri, F., 2014b. A new formulation to model the degradation in structured soils. In: 8th European Conference on Numerical Methods in Geotechnical Engineering. Delft, pp. 97-102.

Roscoe, K. H., Burland, J. B., 1968. On the generalized stress-strain behaviour of wet clay. Engineering Plasticity, $535-609$.

Rotta, G. V., Consoli, N. C., Prietto, P. D. M., Coop, M. R., Graham, J., 2003. Isotropic yielding in an artificially cemented soil cured under stress. Géotechnique 53 (5), 493-501.

Rouainia, M., Muir wood, D., 2000. A kinematic hardening constitutive model for natural clays with loss of structure.

Suebsuk, J., Horpibulsuk, S., Liu, M. D., 2010. Modified Structured Cam Clay: A generalised critical state model for destructured, naturally structured and artificially structured clays. Computers and Geotechnics 37 (7-8), 956-968.

Suebsuk, J., Horpibulsuk, S., Liu, M. D., 2011. A critical state model for overconsolidated structured clays. Computers and Geotechnics 38 (5), 648-658.

Tremblay, H., Leroueil, S., Locat, J., 2001. Mechanical improvement and vertical yield stress prediction of clayey soils from eastern Canada treated with lime or cement. Canadian Geotechnical Journal 38 (3), 567-579.

Vatsala, A., Nova, R., Srinivasa Murthy, B. R., 2001. Elastoplastic Model for Cemented Soils. Journal of Geotechnical and Geoenvironmental Engineering 127 (8), 679-687.

Wissa, A. E., Ladd, C. C., Lambe, T. W., 1965. Effective stress strength parameters of stabilized soils. In: International conference on soil mechanics and foundation engineering. Montréal, pp. 412-416.

Yang, C., Carter, J. P., Sheng, D., 2014. Description of compression behaviour of structured soils and its application 933 (July 2013), 921-933.

Yong, R., Nagaraj, T., 1977. Investigation of fabric and compressibility of a sensitive clay. In: Proceedings of the International Symposium on Soft Clay, Asian Institute of Technology. pp. 327-333.

Zytynski, M., Randolph, M., Nova, R., Wroth, C., 1978. On modelling the unloading-reloading behaviour of soils. International Journal for Numerical and Analytical Methods in Geomechanics 2 (1), 87-93. 